PostScript

\section{LETTERS \\ Serpiginous choroidopathy presenting as choroidal neovascularisation}

Serpiginous choroidopathy is an insidious, relentlessly progressive, idiopathic inflammatory disease affecting the retinal pigment epithelium and inner choroid. Choroidal neovascularisation (CNV) is a well recognised late complication of serpiginous choroidopathy in $10-25 \%$ of affected patients. ${ }^{1}$ In all previously reported cases CNV was recognised at the time of or after the diagnosis of serpiginous choroidopathy was established. ${ }^{2-4}$ We report a patient presenting with $\mathrm{CNV}$ who subsequently developed clinical findings characteristic of serpiginous choroidopathy.

\section{Case report}

A 31 year old man presented with decreased vision in his right eye in July 1997. Examination revealed acuities of 20/40 right eye and 20/20 left eye with normal anterior segments. The right fundus showed subretinal fluid and haemorrhage adjacent to the disc (Fig 1A). The left eye showed an irregularity superior to the optic disc (Fig 1B). The vitreous and fundi were otherwise normal bilaterally. Fluorescein angiography (Fig 2A, B) revealed peripapillary choroidal neovascular membranes in both eyes that were treated with argon laser photocoagulation. In April 1998 and February 1999 the left eye required photocoagulation for recurrent peripapillary CNV. Evaluation for
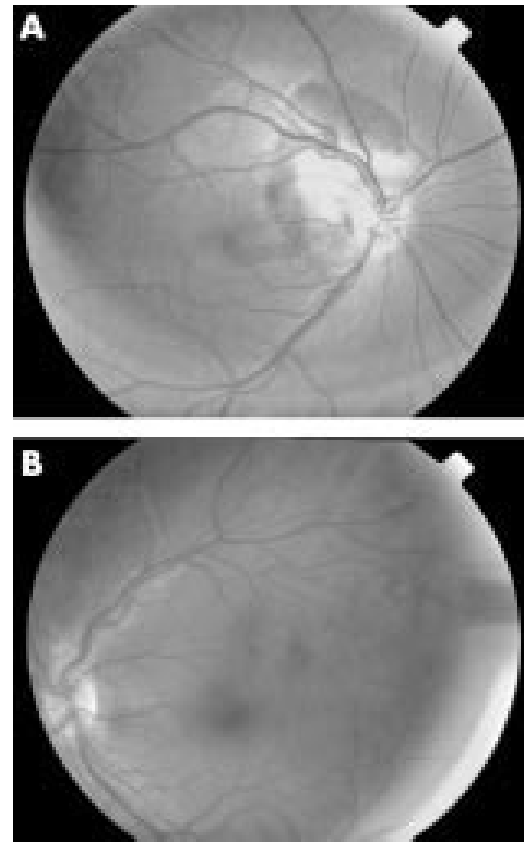

Figure 1 July 1997. (A) The right eye shows subretinal fluid adjacent to the disc surrounded by subretinal haemorrhage extending to the fovea. (B) An undefined irregularity is noted superior to the optic disc of the left eye.
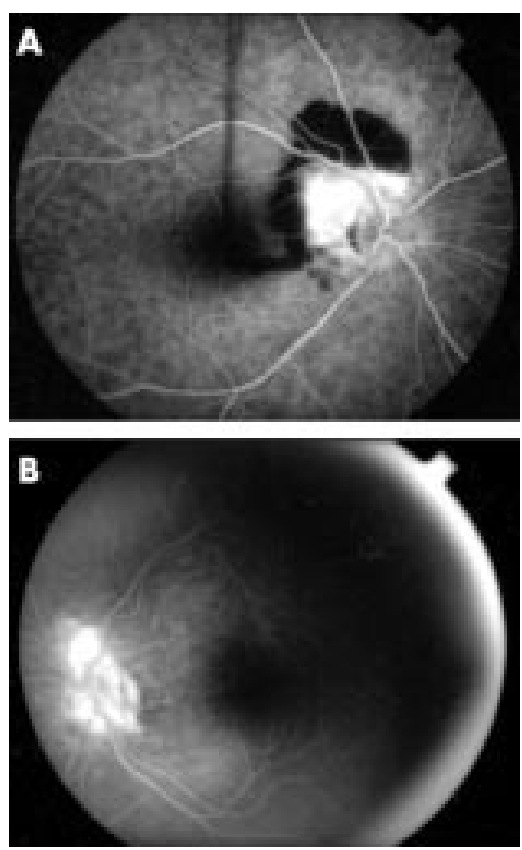

Figure 2 (A) Angiography of the right eye reveals a wedge shaped peripapillary $\mathrm{CNV}$ membrane. (B) A smaller CNV membrane is present angiographically superior to the left optic disc (late phase).
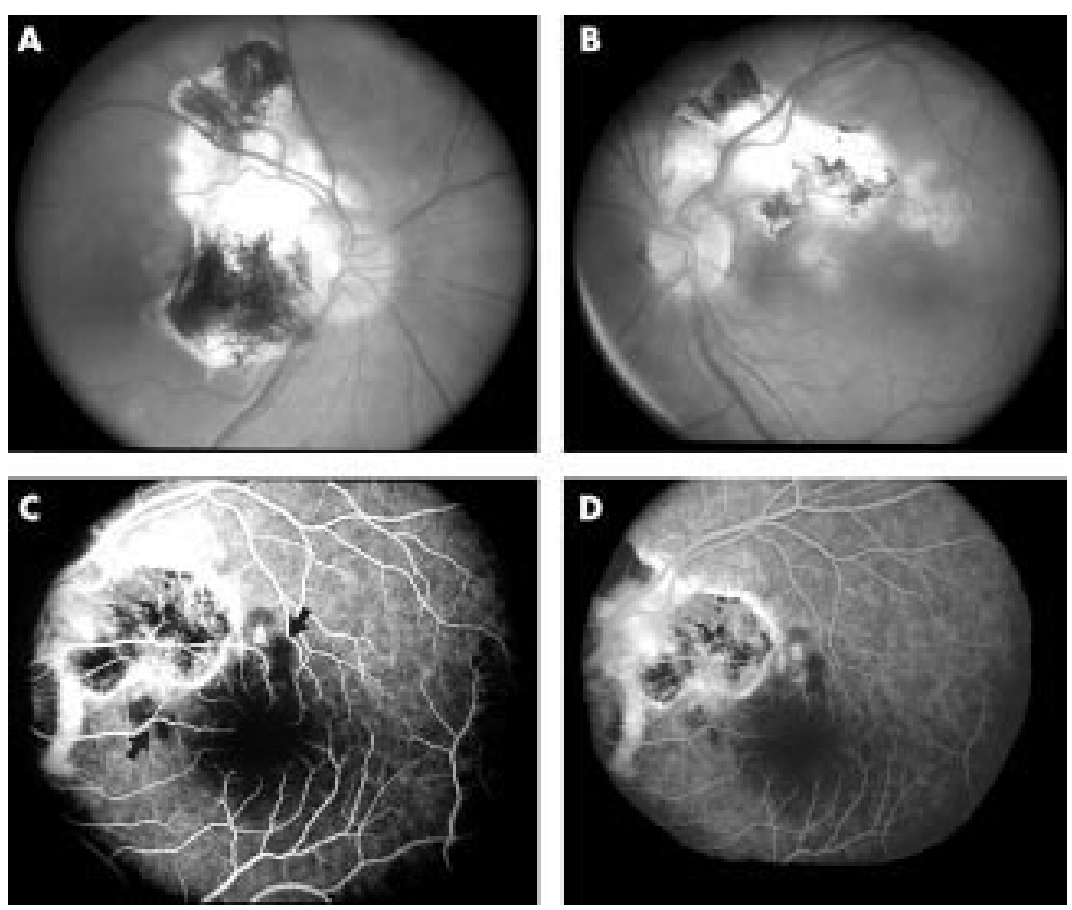

Figure 3 April 2000. (A) The right eye shows a large peripapillary chorioretinal scar resulting from previous laser photocoagulation of the initial CNV lesion. (B) A similar photocoagulation scar is present in the left eye which also shows two non-contiguous active serpiginous lesions. The fluorescein angiogram of the left eye shows early hypofluorescence (C, arrows) corresponding to the locations of the active serpiginous lesions that later become hyperfluorescent (D). 
diagnostic of serpiginous choroidopathy Other causes of posterior uveitis associated with CNV and chorioretinal lesions similar to those seen in our patient include acute posterior multifocal pigmented placoid epitheliopathy (APMPPE), presumed ocular histoplasmosis syndrome (POHS), sarcoidosis, multifocal choroiditis, birdshot chorioretinopathy, and toxoplasmosis. As with most cases of serpiginous choroidopathy, the $\mathrm{CNV}$ in these entities typically occurs late in the disease course.

The exact pathogenesis of idiopathic $\mathrm{CNV}$ is unknown. CNV in eyes with uveitis, however, is believed to develop in direct response to the intraocular inflammation which may alter the balance between vascular growth factors, such as vascular endothelial growth factor (VEGF), and inhibitors. ${ }^{16}$ In the early stages of development active serpiginous lesions and CNV may appear as poorly defined subretinal lesions difficult to differentiate by ophthalmoscopy. Typically with fluorescein angiography classic CNV and serpiginous lesions are readily distinguished as the former shows early hyperfluorescence while the latter characteristically shows early blockage. Occult $\mathrm{CNV}$, which may show subtle or less pronounced early hyperfluorescence with late leakage, however, may be more difficult to distinguish from an early serpiginous lesion.

This case illustrates that serpiginous choroidopathy may present with CNV. In contrast to idiopathic CNV, optimal treatment of CNV in patients with uveitis may require immunosuppressive treatment that addresses the underling ocular inflammation with or without adjunctive laser therapy. ${ }^{16}$ Further investigation is needed to better define the role of emerging therapies for CNV such as photodynamic therapy which may offer promise for the treatment of CNV in uveitis patients.

Financial support: none.

D K Lee

Department of Ophthalmology, Jonas Friendenwald Ophthalmic Institute at Maryland General Hospital

Baltimore, MD, USA

W Augustin, R R Buggage, E B Suhle

Laboratory of Immunology, National Eye Institute National Institutes of Health, Bethesda, MD, USA

Correspondence to: Ronald R Buggage, MD National Eye Institute, National Institutes of Health Bldg 10, Room 10N112, Bethesda, MD 20892-1857, USA; BuggageR@nei.nih.gov

Accepted for publication 30 October 2002

\section{References}

1 Kuo IC, Cunningham ET Jr. Ocular

neovascularization in patients with uveitis. Int Ophthalmol Clin 2000;40: 111 1-26.

2 Jampol LM, Orth D, Daily M, et al.

Subretinal neovascularization with geographic (serpiginous) choroiditis. Am J Ophthalmol 1979;88:683-9.

3 Erkkila H, Laatikainen L. Subretinal and disc neovascularization in serpiginous choroiditis. BrJ Ophthalmol 1982;66:326-31.

4 Blumenkranz MS, Gass JD, Clarkson JG. Atypical serpiginous choroiditis. Arch Ophthalmol 1982;100:1773-5.

5 Erkkila $\mathrm{H}$, Laatikainen L. A follow up study of serpiginous choroiditis. Acta Ophthalmol 1981:59:707-18.

6 Dees C, Arnold JJ, Forrester JV, et al. Immunosuppressive treatment of choroidal neovascularization associated with endogenous posterior uveitis. Arch Ophthalmol 1998;116:1456-61

7 Farah ME, Costa RA, Muccioli C, et al. Photodynamic therapy with verteporfin for subfoveal choroidal neovascularization in Vogt-Koyanagi-Harada syndrome. Am J Ophthalmol 2002;124:137-9.

\section{Optic neuritis in anti-GQ1b positive recurrent Miller Fisher syndrome}

Only five cases of optic nerve involvement in Miller Fisher syndrome (MFS) have been documented in the literature. This report further confirms that optic neuritis may be seen in anti-GQIb positive MFS.

\section{Case report}

This 23 year old woman presented with acute blurry vision, diplopia, and pain with eye movement. Her visual acuity was 20/20 right eye and 20/200 left eye with a left relative afferent pupillary defect (RAPD). She had left red colour desaturation. Her visual field on tangent screen revealed an enlarged left blind spot and a left upper quadrant temporal peripheral field constriction. She had bilateral sixth nerve palsies, nystagmus in all gazes, and left optic disc oedema. After 1 week her visual acuity improved to 20/20 in both eyes, but her left disc remained oedematous. She then developed rapidly progressive gait ataxia to such a degree that she was unable to walk. Dysmmetria and dysdiadochokinesia were more marked in her left upper extremity. She had very mild distal lower extremity weakness, absent lower extremity deep tendon reflexes, and bilateral Babinski's. She also had tingling in her hands and feet and decreased lower extremity vibratory sensation. Her mental status was normal throughout her illness. She was not taking any drugs. A magnetic resonance image (MRI) of the brain and entire spine and MR venogram were all normal. Her cerebrospinal fluid (CSF) opening pressure was $150 \mathrm{~mm} \mathrm{H}_{2} \mathrm{O}$. Her CSF protein was elevated at $70 \mathrm{mg} / \mathrm{dl}$, but CSF glucose and cell count were normal; CSF VDRL, Gram stain, routine bacterial, viral, and fungal cultures were all negative. No oligoclonal bands were seen on CSF electrophoresis. Her visual evoked potential (VEP) revealed a delayed left P100 latency at $131 \mathrm{~ms}$ and her brainstem auditory evoked potential (BAEP) was normal. Electromyogram/nerve conduction study (EMG/NCV) study revealed mildly prolonged median and peroneal F-waves, normal distal motor latencies in her extremities and a reduced left median sensory nerve action potential (SNAP). Anti-GQlb antibody $(162$ EIA U (normal $=100)$ Athena Diagnostics, Worcester, MA, USA) and anti-GMl antibody (1035 EIA U (normal $=800)$ Athena Diagnostics, Worcester, MA, USA) were both positive at high titres. Syphilis and Borrelia serology was normal. Antibodies for acetylcholine receptor, hepatitis A, B, and C; Mycoplasma, Campylobacter jejuni, Lyme, $\mathrm{Hu}$ MaTa, Yo, CV-2, and Ri were all negative. Sedimentation rate, ANA, and c-ANCA were all normal. Serum and urine toxicological screen were both negative. After 5 days of plasmapheresis, her anti-GQlb and anti-GMl antibodies were negative. Her optic disc oedema, ocular motor palsies, and nystagmus immediately resolved, but she continued to walk with assistance. Two months later she had fully recovered. Six months after her recovery she developed a similar recurrence of her neurological symptoms and signs with left optic disc oedema. Her visual acuity at that time was 20/20 right eye and 20/100 left eye. She had a left RAPD and enlarged left blind spot again, but no extraocular motility defects. Her VEP showed a delayed left P100 latency at $142 \mathrm{~ms}$ and her BAEP was normal. Single fibre EMG of her left frontalis muscle revealed no blocking suggestive of a neuromuscular transmission defect. HLA-DR2 allele was positive and HLA-Cw3 allele was negative. Her anti-GQlb antibody (212 EIA U (normal $=100$ ) Athena Diagnostics, Worcester, MA, USA) was elevated again. She underwent plasmapheresis with full recovery in about 6 months.

\section{Comment}

In addition to the classic triad of ophthalmoplegia, ataxia, and arreflexia, visual impairment presenting as optic neuritis may be a feature of anti-GQlb positive recurrent MFS. Only five cases of optic nerve involvement in MFS have been documented in the literature..$^{2-5}$ In the two previously reported cases of visual impairment in MFS, visual evoked potentials were either absent ${ }^{2}$ or suggestive of pre-chiasmal and post-chiasmal visual pathway dysfunction. ${ }^{3}$ Demyelinating optic neuropathies confirmed by VEP were reported in one patient with possible MFS. Two other cases of presumed optic neuritis were associated with anti-GQlb positive MFS. ${ }^{56}$ In the patient presented here, her markedly decreased visual acuity, pain with eye movement, dyschromatopsia, and optic disc oedema that resulted in good visual recovery are all indicative of the diagnosis of optic neuritis. Since high concentrations of GQlb gangliosides are known to be present in the human optic nerve and anti-GQlb antibodies can cross the blood-brain barrier, ${ }^{7}$ the optic disc oedema in this patient could represent an anti-GQ1b IgM complement mediated inflammatory demyelination. Furthermore, her ipsilateral delayed P100 latency is consistent with a pre-chiasmal demyelinating optic neuropathy.

In addition to her optic neuritis, this patient concomitantly demonstrated the classic features of MFS which are the acute onset of external ophthalmoplegia, ataxia of the cerebellar type, and the loss of deep tendon reflexes. ${ }^{1}$ MFS is considered a variant of Guillain-Barré syndrome (GBS) because some patients who present with MFS progress to GBS. ${ }^{8}$ High titres of anti-GQlb IgG antibodies are present in $80 \%$ to $100 \%$ of patients with MFS. ${ }^{8}$ MFS may be immunologically differentiated from GBS by the presence of anti-GQlb and anti-GMl antibodies. Although both anti-GDla IgG and anti-GMl IgG are associated with GBS, ${ }^{9}$ anti-GMl IgG is present in patients with typical MFS who have limb weakness, ${ }^{9}$ as in this patient. As further evidence linking this antibody to MFS, ${ }^{8}$ the decrease in anti-GQlb antibody levels after plasmapheresis correlated with the clinica recovery in this patient. Therefore, the elevated titres of anti-GQlb and anti-GMl antibodies, along with the clinical triad of ophthalmoplegia, arreflexia, and ataxia in thi patient all support the diagnosis of MFS, and not GBS.

In rare cases, MFS has been known to recur. This patient presented with a relapse of simiar clinical features 6 months after recovery from her initial episode. In the study done by Chida et al, ${ }^{10}$ patients with recurrent MFS appeared to have similar HLA typing characteristics as the non-recurring ones. Both types shared HLA-DR2 and Cw3 alleles, but the frequency of HLA-DR2 was slightly higher in the patients with recurrent MFS. ${ }^{10}$ Therefore, thi patient's HLA-DR2-positive status may have been a risk factor for her recurrence of MFS.

This case report emphasises that optic neuritis may be a central nervous system feature that should be recognised as part of the Mille Fisher syndrome. The presence of both antiGQlb IgG and anti-GMl IgG in this patien provides immunological evidence supportive 
of typical MFS. The delayed P100 latency in her VEP also provides electrophysiological evidence that the optic nerve is affected in anti-GQlb antibody positive MFS. Furthermore, this is the first documented case known to the author of optic neuritis in the recurrent subtype of MFS which is associated with a higher frequency of the HLA-DR2 allele.

J W Chan

Department of Internal Medicine Division of Neurology, University of Nevada School of Medicine, 1707 W Charleston Blvd, Suite 220, Las Vegas, Nevada 89102, USA; worjun@aol.com

Accepted for publication 6 January 2003

\section{References}

1 Fisher $\mathbf{M}$. An unusual variant of acute idiopathic polyneuritis (syndrome of ophthalmoplegia, ataxia and areflexia). $N$ Engl J Med 1956;225:57-65.

2 Ouhabi H, Bourazza A, Rouimi A, et al. [Bilateral optic neuritis and ponto-mesencephalic involvement shown by MRI in Miller-Fisher syndrome.] [In Freud] Rev Neurol (Paris) 1998;154:780-2.

3 Toshniwal P. Demyelinating optic neuropathy with Miller Fisher syndrome. The case for overlap syndromes with central and periphera demyelination. J Neurol 1987;234:353-8.

4 Carvalho AA, Galvao MD, Rocha MS, et al. Miller Fisher syndrome and optic neuritis: case report. Arq Neuropsiquiatr 2000;58: $1115-7$.

5 Colding-Jorgensen E, Vissing J. Visual impairment in anti-GQ1b positive Miller Fisher syndrome. Acta Neurol Scand 2001:103:259-60.

6 Sasaki Y, Takubo H, Arai T, et al. Atypical Fisher syndrome with optic nerve involvement No To Shinkei 2001;53:571-3.

7 Yoshino H, Maeda Y, King M, et al. Sulfated glucuronyl glycolipids and gangliosides in the optic nerve of humans. Neurology 1993:43:408-11.

8 Chiba A, Kusunoki S, Shimizu T, et al. Serum $\lg G$ antibody to ganglioside GQ1b is a possible marker of Miller Fisher syndrome. Ann Neurol 1992:31:677-9.

9 Kornberg AJ, Pestronk A, Bieser K, et al. The clinical correlates of high-titer $\lg G$ anti-GMI antibodies. Ann Neurol 1994;35:234-7.

10 Chida K, Nomura H, Konno H, et al. Recurrent Miller Fisher syndrome: clinical and laboratory features and HLA antigens. $J$ Neurol Sci 1999;165:139-43.

\section{Ocular myasthenia gravis and inflammatory bowel disease: a case report and literature review}

Myasthenia gravis has been reported to be associated with both ulcerative colitis (UC) and Crohn's disease (CD).$^{1-3}$ The link between inflammatory bowel disease (IBD) and myasthenia gravis (MG) is thought to be related to the production of autoantibodies. Myasthenia gravis is also associated with other autoimmune diseases including alopecia, lichen planus, vitiligo, and systemic lupus erythematosus.

Similarly, IBD frequently presents with other autoimmune disorders. One study demonstrated a $9.4 \%$ prevalence of autoimmune disorders in patients with UC including sclerosing cholangitis, thyroid disorders, vitiligo, insulin dependent diabetes mellitus, thyroid disease, pernicious anaemia, scleroderma, and seropositive rheumatoid arthritis. ${ }^{45}$ Despite the association between MG and other autoimmune disorders, there are relatively few reports of ocular findings as the presenting sign of $\mathrm{MG}$ in patients with IBD.

\section{Case report}

A 21 year old African-American male, with a medical history of biopsy proved ulcerative

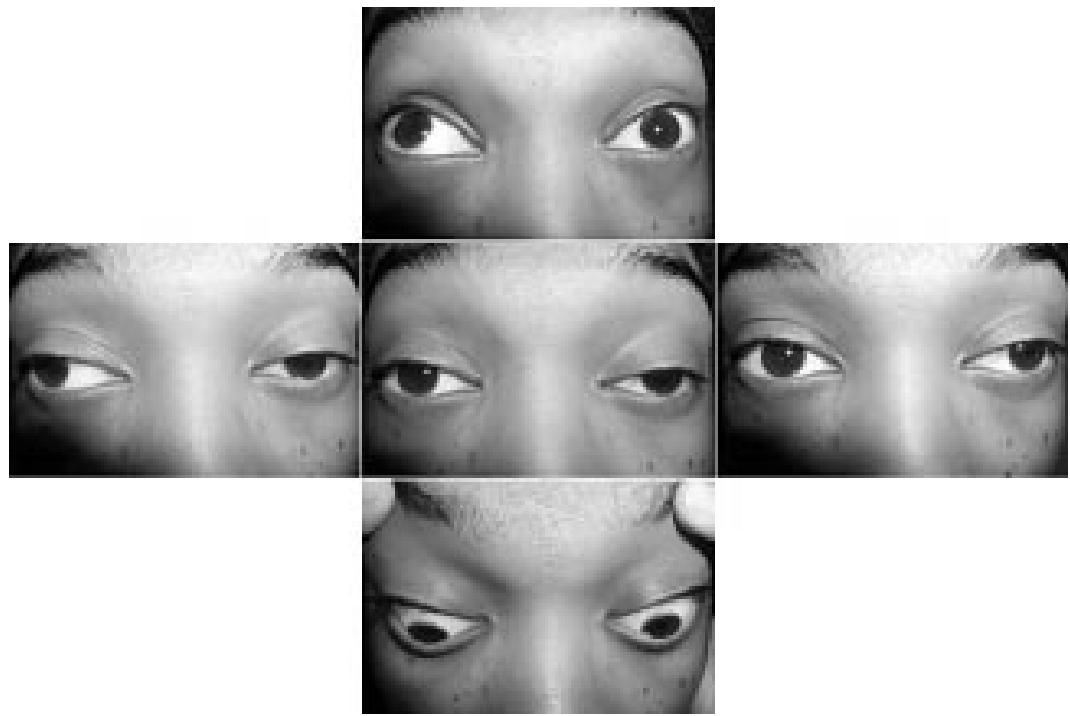

Figure 1 External photograph shows ptosis of the left upper eyelid, restriction of all extraocular movements of the left eye, and an elevation and adduction deficit of the right eye. colitis diagnosed in 1995, focal segmental glomerular sclerosis determined by renal biopsy in 1995, and primary sclerosing cholangitis determined by liver biopsy in 2000 presented to the neuro-ophthalmology service with complaints of binocular diplopia and ptosis of the left upper eyelid. Both the diplopia and the ptosis were better in the morning and worsened during the course of the day. His ulcerative colitis had been in remission for the past 5 years without medication.

Best corrected visual acuity was 20/25 in each eye. The external examination revealed ptosis of the left upper eyelid that worsened in sustained upgaze. He had limited extraocular motility in all fields of gaze (Fig 1). The remainder of the neuro-ophthalmic examination was normal and he had no difficulty with speech or swallowing.

Laboratory evaluation revealed a positive acetylcholine receptor antibody and normal thyroid function studies. There was no evidence of a thymic mass on magnetic resonance imaging of the chest.

The patient returned to the emergency room 1 week later with difficulty swallowing and shortness of breath. He was hospitalised for plasmapheresis and upon discharge treated with imuran, prednisone, and mestinon. One month later his ptosis resolved and his extraocular motility was normal.

\section{Comment}

Autoimmune disorders, including MG, occur more frequently in UC than in CD. ${ }^{3}$ It is not clear how many other cases of IBD manifested with ocular presentations as the initial finding of MG as in our case report. Our literature review revealed only one other purely ocular presentation of myasthenia associated with ulcerative colitis; however, details of the ocular examination were not included. ${ }^{5}$ Another report, of a 21 year old woman with a 3 year history of Crohn's disease, documented diplopia and unilateral ptosis as the initial findings of $\mathrm{MG}^{3}{ }^{3}$ She was found to have acetylcholine receptor antibodies and her ocular findings improved with pyridostigmine.

Because of the relatively few reports of ocular myasthenia in patients with IBD we reviewed the English literature and found four additional reports of MG in patients with IBD. Based on these four reports and the three (including the present report) with ocular MG in patients with IBD (Table 1), the mean duration of IBD before the diagnosis of $M G$ was 10 years.

Autoimmune dysregulation is the central defect in both MG and IBD. Both IBD and MG may be associated with an elevated carcinoembryonic antigen (CEA) and decreased peripheral lymphocyte counts that subsequently normalise following thymectomy. ${ }^{6}$ Some studies have shown abnormal thymic involution and the presence of an abnormal ratio of $\mathrm{T}$ suppressor to $\mathrm{T}$ helper cells in both MG and UC, while others have noted a decline in suppressor $\mathrm{T}$ cells and an increase in
Table 1 Previous reports of myasthenia gravis occurring in patients with inflammatory bowel disease

\begin{tabular}{|c|c|c|c|c|c|}
\hline Reference & $\begin{array}{l}\text { Age } \\
\text { (years) }\end{array}$ & Sex & IBD & $\begin{array}{l}\text { Duration of IBD } \\
\text { before diagnosis } \\
\text { of MG (years) }\end{array}$ & $\begin{array}{l}\text { AchR antibody } \\
\text { reactivity }\end{array}$ \\
\hline Miller $1971^{5}$ & 35 & Male & UC & 13 & Unknown \\
\hline Tan $1974^{4}$ & 38 & Male & UC & 12 & Unknown \\
\hline Martin et al, $1991^{1}$ & 63 & Male & $C D$ & 15 & Positive \\
\hline Gower-Rousseau et al, $1993^{8}$ & 27 & Female & UC & 10 & Positive \\
\hline Finnie et al, $1994^{3}$ & 21 & Female & $C D$ & 3 & Positive \\
\hline Lossos et al, $1995^{\circ}$ & 11 & Male & $C D$ & 9 & Unknown \\
\hline Present report & 21 & Male & UC & 7 & Positive \\
\hline
\end{tabular}

$\mathrm{IBD}=$ inflammatory bowel disease, $M G=$ myasthenia gravis, $\mathrm{AchR}=$ acetylcholine receptor, $\mathrm{UC}=$ ulcerative colitis, $C D=$ Crohn's disease. 
immature helper $\mathrm{T}$ cells suggesting migration without normal maturation. ${ }^{2}$

The immunological link between MG and IBD is highlighted by two reports of patients undergoing surgical treatment. One report of a patient with both MG and CD documented improvement in perineal and perianal disease following thymectomy for severe uncontrolled MG. ${ }^{3}$ Another patient with both MG and UC demonstrated regression of the myasthenia following proctolectomy. ${ }^{8}$

Although the simultaneous occurrence of these two autoimmune disorders is uncommon, it is important to understand that ocular findings may be the initial manifestation of MG in patients with IBD.

The authors have no proprietary interest in any contents of this manuscript

R Foroozan, R Sambursky Neuro-Ophthalmology Service, Baylor College of Medicine, 6565 Fannin, NC-205, Houston, TX 77030, USA

Correspondence to: Dr Rod Foroozan Neuro-Ophthalmology Service, Baylor College of Medicine, 6565 Fannin, NC-205, Houston, TX 77030, USA

Accepted for publication 10 January 2003

\section{References}

1 Martin RW, Shah A. Myasthenia gravis coexistent with Crohn's disease. J Clin Gasteroenterol 1991;13:112-13.

2 Souadiitian JV, Enriquez P, Silverstein MN, et al. The spectrum of disease associated with thymoma. Coincidence or syndrome? Arch Intern Med 1974;134:374-9.

3 Finnie IA, Shields R, Sutton R, et al. Crohn's disease and myasthenia gravis: a possible role for thymectomy. Gut 1994;35:278-9.

4 Tan RS. Ulcerative colitis, myasthenia gravis, atypical lichen planus, alopecia areata, vitiligo. Proc R Soc Med 1974;67: 195-6.

5 Miller TN. Myasthenia gravis, ulcerative colitis and lichen planus. Proc $R$ Soc Med 1971;64:806.

6 Papatestas AE, Kim U, Genkins G, et al. The association of carcinoembryonic antigen and peripheral lymphocytes. Surgery 1974:78:343-48.

7 Aiso S, Yoshida T, Watanabe $M$, et al. Characterization of thymus cells in hyperplastic thymuses in patients with myasthenia gravis and ulcerative colitis with monoclonal antibodies. J Clin Lab Immunol 1984:13:137-9.

8 Gower-Rousseau C, Reumaux D, Bellard M et al. Remission of myasthenia gravis after proctolectomy in a patient with ulcerative colitis. Am J Gastroenterol 1993;88:1 136-8.

9 Lossos A, River Y, Eliakim A, et al. Neurologic aspects of inflammatory bowel disease. Neurology 1995;45(Pt 1):416-21.

\section{Magnetic resonance imaging findings in malignant melanoma of the lacrimal sac}

A case of primary malignant melanoma of the lacrimal sac is presented. This is the first report of the preoperative magnetic resonance imaging (MRI) findings of malignant melanoma of the lacrimal sac.

\section{Case report}

A 54 year old Chinese woman was referred to an ophthalmologist complaining of a 6 month history of left sided bloody tears and epistaxis. she had a firm, non-tender left medial canthal swelling, and syringing revealed left nasolacrimal duct (NLD) obstruction. Ocula and periorbital examination was otherwise normal. A dacryocystogram (DCG) demonstrated a filling defect in the lacrimal sac with NLD obstruction.
An ENT opinion was sought, and nasal examination revealed left sided septal deviation, with no obvious cause for the epistaxis.

Computed tomography (CT) of the head and orbits demonstrated a left lacrimal sac lesion extending into the NLD with proximal dilation of the duct and no apparent bone erosion (Fig lA) MRI confirmed the presence of a lacrimal sac lesion with intermediate signal intensity on $\mathrm{T} 1$ and $\mathrm{T} 2$ weighted images (Fig 2A, B) The lesion enhanced with intravenous gadolinium.

An incisional biopsy of the lacrimal sac (Fig IB) under frozen section control, and paraffin sections, confirmed malignant melanoma.

A full medical review, including MRI of the chest and abdomen, and liver function tests, excluded tumour elsewhere. However, abdominal MRI and ultrasound revealed a co-incidental polycystic liver.

Three weeks after biopsy, a wide local excision including the medial upper and lower eyelids, dacryocystectomy and medial maxillectomy was performed. A tumour, confined to the sac, and invasion through the medial wall of the upper NLD, into the lateral wall of the nose, and apposing nasal septal mucosa, was seen peroperatively and confirmed histologically.

She underwent postoperative adjuvant radiotherapy ( 55 grays) and to date, 4 months later, remains well.

\section{Comment}

Malignant melanoma of the lacrimal sac is rare accounting for $5 \%$ of lacrimal sac tumours. ${ }^{12}$ It has an unfavourable prognosis compared with other causes of lacrimal sac tumour, and is considered more aggressive than cutaneous malignant melanoma. ${ }^{23} \mathrm{Re}-$ sponse to treatment is generally poor, with up to $80 \%$ of cases recurring within 2 years.
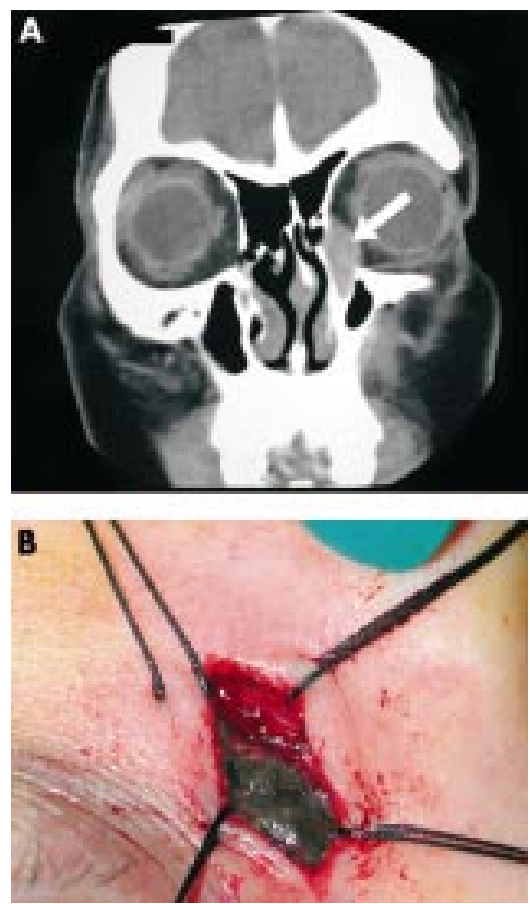

Figure 1 (A) Coronal CT scan demonstrating a solid mass of the left lacrimal sac with proximal dilation of the nasolacrimal duct (arrow). (B) Incisional biopsy with lacrimal sac opened and melanoma visible.
Radiological features of lacrimal sac tumours include filling defects on DCG and mass lesions on CT. ${ }^{1-3}$ However, to the authors knowledge, this is the first report of the MRI findings of malignant melanoma of the lacrimal sac.

Owing to the paramagnetic properties of melanin, malignant melanoma appears hyperintense on $\mathrm{Tl}$ weighted imaging, and hypointense on T2 weighted imaging. ${ }^{4} \mathrm{~A}$ study of six mucosal melanomas of the head and neck found that on $\mathrm{Tl}$, five lesions were hyperintense and one was isointense. ${ }^{5}$ On T2, five were of mixed intensity and one was isointense. They concluded that hyperintensity on $\mathrm{Tl}$ of mucosal melanomas was characteristic but not universal.

The majority of malignant lacrimal sac tumours are epithelial in origin. ${ }^{3}$ Imaging features suggesting malignancy include invasion of bone, rapid growth, and irregular margins with skin fixation. On MRI, the majority of epithelial tumours have intermediate signal intensity on $\mathrm{Tl}$ and high $\mathrm{T} 2$ signal intensity. High tumour cellularity is associated with intermediate to low T2 signal intensity.

High signal intensity on $\mathrm{Tl}$ is not specific for malignant melanoma. Subacute haemorrhage caused by the presence of methaemoglobin is more likely and although melanoma may undergo intratumoral haemorrhage, other tumours with a tendency to bleed include small cell lung carcinoma, choriocarcinoma, and renal cell carcinoma metastases. Less likely causes include fat containing tumours (lipoma, dermoid, and teratoma)
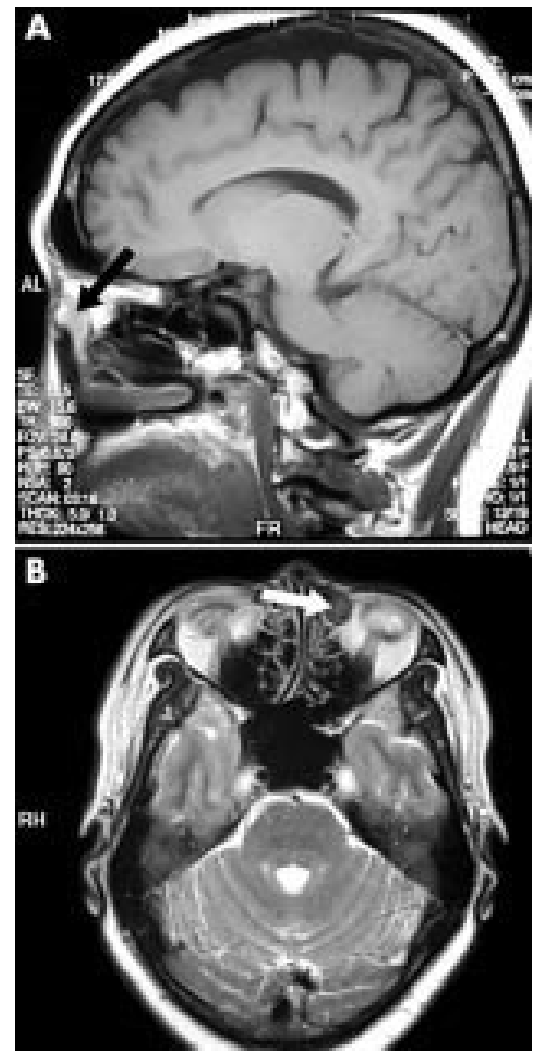

Figure 2 (A) T1 weighted sagittal MRI demonstrating intermediate signal intensity mass lesion of the lacrimal sac and proximal nasolacrimal duct (arrow). (B) T2 weighted axial MRI demonstrating intermediate signal intensity mass lesion of the left lacrimal sac (arrow). 
requiring MRI fat suppression methods, paramagnetic material (manganese, iron, and copper), and very high (non-paramagnetic) intratumoral protein concentration.

MRI has been reported as a useful investigative tool in the assessment of lacrimal disease owing to its ability to delineate soft tissues. Intravenous and intracanalicular gadolinium adds useful information on lesional enhancement and lacrimal apparatus structure and function. ${ }^{8}$ The predictive value of MRI for lacrimal sac melanoma, however, appears to be variable. Hyperintensity on Tl relies on the paramagnetic properties of melanin, the presence of which is variable in amelanotic melanoma. This is supported by our case, where only moderate Tl hyperintensity with contrast enhancement was demonstrated.

K Billing, R Malhotra, D Selva Oculoplastic and Orbital Unit, Department of Ophthalmology, Royal Adelaide Hospital, The University of Adelaide, Australia

S Saloniklis, J Taylor MRI Unit, Department of Radiology, Royal Adelaide Hospital, Adelaide, Australia

S Krishnan

Department of Otolaryngology, Royal Adelaide Hospital, Adelaide, Australia

Correspondence to: Dr Dinesh Selva, Oculoplastic and Orbital Clinic, Department of Ophthalmology, Royal Adelaide Hospital, North Terrace, Adelaide, South Australia 5000 Awestwoo@mail.rah.sa.gov.au

Accepted for publication 10 January 2003

\section{References}

1 Owens RM, Wax MK, Kostik D, et al. Malignant melanoma of the lacrimal sac. Otolaryngol Head Neck Surg

1995; 113:634-40.

2 Pe'er JJ, Stefanyszyn M, Hidayat AA. Nonepithelial tumors of the lacrimal sac. Am J Ophthalmol 1994;118:650-8.

3 Stefanyszyn M, Hidayat AA, Pe'er JJ, et al. Lacrimal sac tumors. Ophthalmic Plast Reconstr Surg 1994;10:169-84.

$4 \mathrm{Kim}$ SH, Han MH, Park SW, et al.

Radiologic-pathologic correlation of unusual lingual masses. Part II: Benign and malignant tumors. Korean J Radiol 2001 ;2:42-51.

5 Yoshioka H, Kamada T, Kandatsu S, et al. MRI of mucosal malignant melanoma of the head and neck. J Comput Assist Tomogr 1998:22:492-7.

6 Stark DD, Bradley WD. Magnetic resonance imaging. 3rd ed. St Lovis: Mosby, 1999.

7 Atlas SW. Magnetic resonance imaging of the brain and spine. 3rd ed. Philadelphia: Lippincott Williams and Wilkins, 2002

8 Goldberg RA, Heinz GW, Chiu L. Gadolinium magnetic resonance imaging dacryocystography. Am J Ophthalmol 1993;115:738-41.

\section{Photodynamic therapy for recurrent myopic choroidal neovascularisation after limited macular translocation surgery}

Limited macular translocation (LMT) is one of the treatment options for subfoveal choroidal neovascularisation (CNV) resulting from pathological myopia. ${ }^{1}$ The fundamental surgical principle involves the transposition of the foveal neurosensory retina to a new site with more healthy underlying retinal pigmen epithelium. ${ }^{12}$ Direct laser photocoagulation is usually employed as an adjunct measure in eradicating the original CNV after the surgery. It has been observed that geometrically sizeable translocation is a prerequisite for a long term surgical success. ${ }^{2}{ }^{3}$ The degree of translocation is, however, not often predictable and any ineffective displacement may render the subsequent laser photocoagulation extremely difficult or even impossible to perform. ${ }^{24}$ As a result, the recurrent or persistent $\mathrm{CNV}$ intruding the newly relocated fovea may jeopardise the final visual outcomes. ${ }^{45}$ Photodynamic therapy (PDT) may be considered a viable adjunct treatment option in such circumstance.

\section{Case report}

A 41 year old woman with pathological myopia of -11.0 dioptres in both eyes presented with a subfoveal CNV and subretinal haemorrhage in her right eye in July 2000. The best corrected visual acuity (BCVA) was 5/200 in her right eye and 20/30 in her left eye. LMT with superotemporal $6 \mathrm{~mm}$ scleral imbrication was performed in July 2000. The operation was uneventful and an inferior displacement of the fovea by $600 \mu \mathrm{m}$ was achieved The CNV, however, was still located in the vicinity of the juxtafoveal area and therefore laser photocoagulation, bearing the potential risk of late creeping scar, was not suggested. At the 4 months postoperative visit, her left BCVA was $20 / 200$ and the original CNV became more fibrotic with minimal leakage upon fluorescein angiogram. Nevertheless, she came back at 5 months with a return of metamorphosia and a drop in her right vision from 20/200 to 10/200. Dilated fundus examination showed a tiny patch of submacular haemorrhage in direct continuity with the old fibrotic scar (Fig lA). Fluorescein angiogram of the early phase demonstrated a fresh recurrent $\mathrm{CNV}$ budding out from the origina fibrotic $\mathrm{CNV}$ and extending to the centre of the foveolar avascular zone (Fig lB). Moderate fluorescein leakage could be seen in the late phase (Fig lC). Treatments comprising revision macular translocation surgery, submacular surgery, photodynamic therapy, and
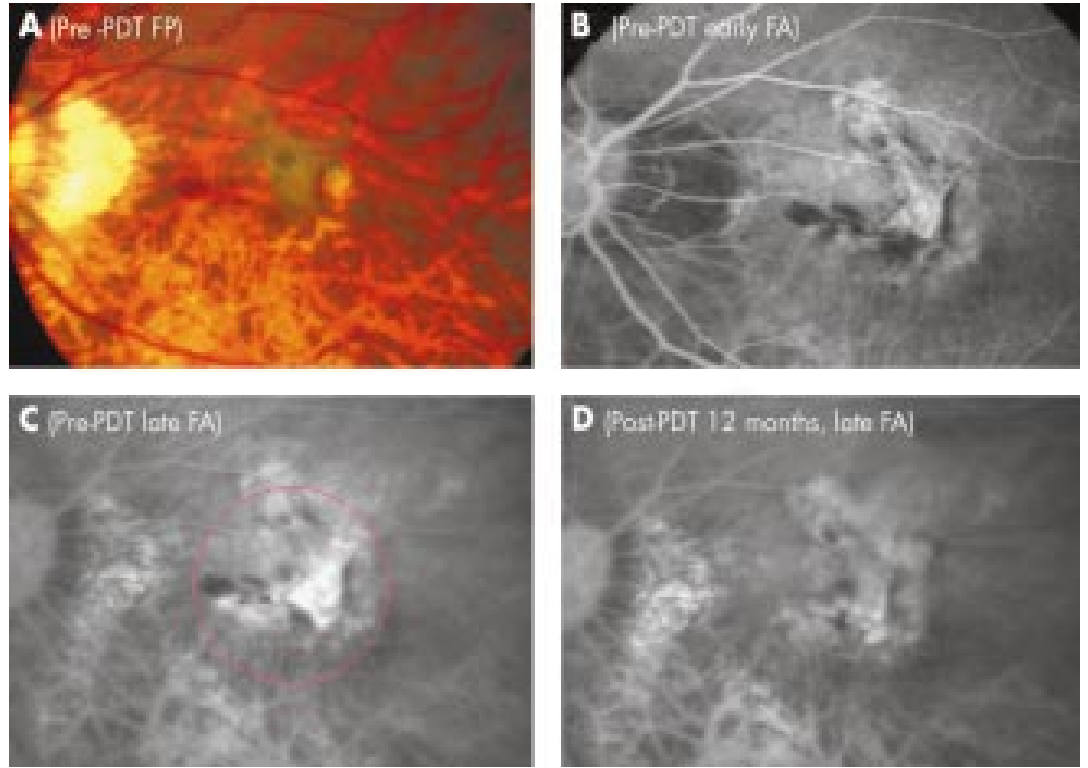

Figure 1 Right eye with recurrent myopic CNV after LMT. (A) Fundus photograph of the patient showing the recurrent part of CNV budding from the original one with haemorrhage involving the subfoveal area. (B) Early phase fluorescein (FA), demonstrating the filling of choroidal vascular complex with early hyperfluorescence. (C) Late phase FA showing late moderate fluorescence leakage from the CNV. Photodynamic therapy (PDT) with the size of the laser spot as marked was delivered. (D) Late phase FA at 12 months revealing a complete regression of the recurrent $C N V$ and late scar staining of the original CNV. 
Its clinical indications and applications are expanding. ${ }^{7}$ Its minimal invasiveness and clinical efficacy make it a safer and visually desirable supplementary treatment in recurrent CNV after LMT. In our patient, the complete closure of $\mathrm{CNV}$ was achieved with concomitant vision improvement after a single session of PDT without evidence of recurrence at 24 months.

Financial interest: Nil.

Financial support: Nil.

W-M Chan, D S C Lam, D T L Liu, T-H Wong, K S C Yuen

Department of Ophthalmology and Visual Sciences, The Chinese University of Hong Kong, Hong Kong

Correspondence to: Dr Wai-Man Chan, Department of Ophthalmology and Visual Sciences, The Chinese University of Hong Kong, Hong Kong Eye Hospital, 147K Argyle Street, Kowloon, Hong Kong; cwm6373@netvigator.com

Accepted for publication 12 January 2003

\section{References}

1 Tano Y. Pathologic myopia: where are we now? Am J Ophthalmol 2002; 134:645-60.

2 Lewis H, Kaiser PK, Lewis S, et al. Macular translocation for subfoveal choroidal neovascularization in age-related macular degeneration: a prospective study. Am J Ophthalmol 1999;129:135-46.

3 Fujii GY, Humayun MS, Pieramici DJ, et al, Initial experience of inferior limited macular translocation for subfoveal choroidal neovascularization resulting from causes other than age-related macular degeneration. $\mathrm{Am} J$ Ophthalmol 2001;131:90-100.

4 Fujii GY, Humayun MS, Pieramici DJ, et al. Inferior limited macular translocation for subfoveal choroidal neovascularization secondary to age-related macular degeneration: 1-year visual outcome and recurrence report. Am J Ophthalmol 2002; 134:69-74.

5 Hamelin N, Glacet-Bernard A, Brindeau C, et al. Surgical treatment of subfoveal neovascularization in myopia: macular translocation vs surgical removal. Am J Ophthalmol 2002;133:530-6.

6 Treatment of Age-Related Macular Degeneration with Photodynamic Therapy (TAP) Study Group. Photodynamic therapy of subfoveal choroidal neovascularization in age-related macular degeneration with verteporfin: two-year results of 2 randomized clinical trials-TAP Report 2. Arch Ophthalmol 2001;119:198-207.

7 Sickenberg $M$, Schmidt-Erfurth U, Miller JW, et al. A preliminary study of photodynamic therapy using verteporfin for choroidal neovascularization in pathologic myopia, ocular histoplasmosis syndrome, angioid streaks, and idiopathic causes. Arch Ophthalmol 2000;118:327-36.

\section{Acquired Glanzmann's thrombasthenia causing prolonged bleeding following phacoemulsification}

Phacoemulsification under topical anaesthesia using clear corneal incision is not a challenging procedure for the haemostatic system. In patients with known bleeding diathesis, this may be the procedure of choice to remove cataract. We report a patient who bled continuously for 36 hours following phacoemulsification under topical anaesthesia through a clear corneal incision. This was managed by using a topical haemostatic agent that has not been used in ophthalmic surgery before. Extensive haematological evaluation revealed the underlying cause to be an acquired form of Glanzmann's thrombasthenia, a very rare condition. ${ }^{12}$

\section{Case report}

A 79 year old woman underwent left phacoemulsification with intraocular lens implantation under topical anaesthesia through a clear corneal temporal incision. The procedure was uneventful but she was seen to bleed from the operated eye in the recovery room. The eye was patched but the bleeding continued soaking the pads. When re-examined 2 hours later as there was continuous bleeding, the eye was patched with gentle pressure. Examination the next day showed that the bleeding was persistent. Pressure bandage was reapplied. Examination in the operating theatre confirmed the conjunctival origin of the bleeding from the site where the left handed surgeon held the conjunctiva during surgery. Cauterisation and an attempt to suture the conjunctiva were unsuccessful. It was decided that the safest option was to use a small piece of oxidised regenerated cellulose (Surgicel, Ethicon) on the bleeding site and patch the eye.

The piece of Surgicel with clotted blood that was lying loose on the conjunctiva was removed at review 24 hours later. The conjunctival site had stopped bleeding with evidence of altered blood on the surface where Surgicel had been applied (Fig lA). At her last review 8 weeks later, she was found to have a corrected visual acuity of 6/18 due to preexistent macular changes secondary to retinal detachment that was reattached in 1976. The conjunctiva had healed well (Fig 1B). The patient had previously undergone an uneventful phacoemulsification and intraocular lens implantation in her right eye under subTenon's anaesthesia.

The patient's recent medical history was significant for recurrent admissions elsewhere for investigation of severe anaemia following gastrointestinal bleeding. Platelet count and clotting screen had been normal. Angiodysplasia of stomach and duodenum were treated with laser and angiodysplasia of colon was treated by hemicolectomy. Three episodes of epistaxis and an episode of vaginal bleeding were managed conservatively. She
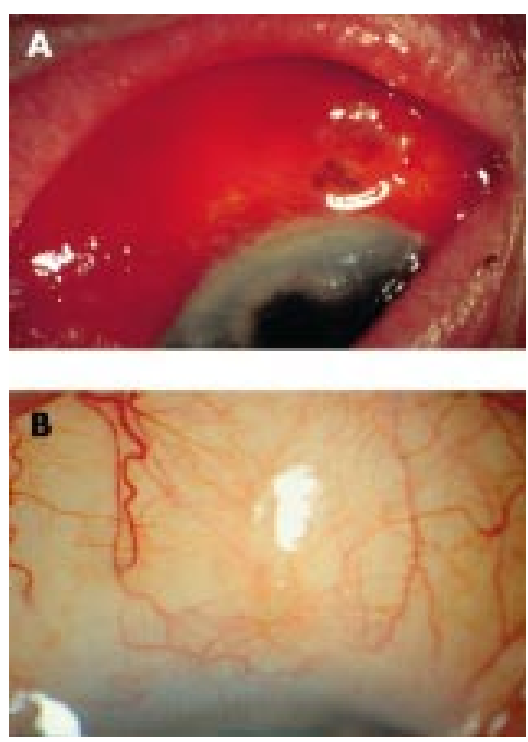

Figure 1 (A) Conjunctival site immediately after removal of Surgicel. (B) Healed conjunctival bleeding site. had received 60 units of blood transfusion over a period of l year. Interestingly, she had appendicectomy and multiple dental extractions elsewhere many years previously without any significant bleeding. She has not been on any antiplatelet agents or anticoagulants. There was no family history of bleeding disorders.

A defect in the platelet function was suspected, as her coagulation screen including the platelet count was normal. Platelet aggregation tests showed no aggregation against any agonists other than ristocetin, which is dependent on platelet glycoprotein Ib. The platelets showed normal surface levels of glycoprotein antigens IIbIIIa and Ib. The patient's serum showed presence of inhibitory antibody against glycoprotein IIbIIIa. This led to a diagnosis of acquired Glanzmann's syndrome, an extremely rare condition of autoimmune thrombasthenia. No underlying malignant, autoimmune, or lymphoproliferative disorder had been identified as a cause for this patient's acquired Glanzmann's thrombasthenia.

\section{Comment}

The patient described had uncontrollable bleeding for 36 hours following a procedure, which is generally considered safe in patients with a bleeding disorder. She developed bleeding from the conjunctival site where the surgeon grasped the conjunctiva during certain stages of the procedure. One would usually not expect any significant bleeding from this site; however, in a patient with compromised haemostasis the bleeding may be prolonged. Although the bleeding was no more than a gentle ooze at any point in time it was persistent enough for 36 hours before the topical haemostatic material Surgicel had been put to use. The consequences of an intraocular bleed may have seriously threatened her sight. ${ }^{3}$

We are not aware of any reports of the use of Surgicel in ophthalmic surgery. All reports of its use are in other fields of surgery. ${ }^{45}$ This material is supposed to swell up with blood and form a gelatinous mass that aids in the formation of clot. It acts as a haemostatic adjunct. The exact mode of its action in this patient with antiplatelet antibodies is unclear. Our experience shows that oxidised regenerated cellulose (Surgicel) may have a role in ophthalmic surgery especially in lacrimal and orbital surgery, when faced with bleeding that is difficult to stop. Various cautionary tales associated with use of Surgicel have been reported. ${ }^{6-8}$

Our report suggests that in the presence of a severe bleeding disorder, clear corneal phacoemulsification under topical anaesthesia may not be totally safe. When performing such a procedure in a patient with known bleeding disorder it may be safe to take all the necessary precautions in consultation with a haematologist to avoid a serious bleed that may be sight and life threatening. There may be a role for haemostatic agents like Surgicel.

S Dinakaran, M P Edwards

Department of Ophthalmology, A-Floor, Royal Hallamshire Hospital, Sheffield, UK

K K Hampton

Department of Haematology, Royal Hallamshire Hospital, Sheffield, UK 
Correspondence to: S Dinakaran, Department of Ophthalmology, A-Floor, Royal Hallamshire Hospital, Sheffield, UK; sdinakaran@yahoo.com

Accepted for publication 20 January 2003

\section{References}

1 George JN, Caen JP, Nurden AT.

Glanzmann's thrombasthenia: the spectrum of clinical disease. Blood 1990;75:1383-95.

2 Greaves M, Pickering C, Porter NR, et al.

Acquired Glanzmann's thrombasthenia. Blood 1983;61:209.

3 Saatci AO, Kuvaki B, Oner FH, et al. Bilatera massive choroidal hemorrhage secondary to Glanzmann's syndrome. Ophthalmic Surg Lasers 2002;33:148-51.

4 Aidonopoulos AP, Papavramidis ST, Goutzamanis GD, et al. A simple and safe method for preservation of the injured spleen. Injury 1993;24:300-2

5 Davidson BR, Burnett S, Javed MS, et al. Experimental study of a novel fibrin sealant for achieving haemostasis following partial hepatectomy. Br J Surg 2000;87:790-5.

6 Kothbauer KF, Jallo Gl, Siffert J, et al. Foreign body reaction to hemostatic materials mimicking recurrent brain tumor. Report of three cases. J Neurosurg 2001:95:503-6.

7 Young ST, Paulson EK, McCann RL, et al. Appearance of oxidized cellulose (Surgicel) on postoperative CT scans: similarity to postoperative abscess. . Am J Roentgenol 1993:160:275-7.

8 Buckley SC, Broome JC. A foreign body reaction to Surgicel mimicking an abscess or tumour recurrence. $\mathrm{Br} J$ Neurosurg

1995:9:561-3.

\section{Propionibacterium acnes endophthalmitis diagnosed by microdissection and PCR}

Although Propionibacterium acnes, a Gram positive anaerobic bacillus, is the most commonly identified cause of delayed onset postoperative endophthalmitis, routine vitreous cultures are frequently inadequate for its diagnosis. This case describes the utility of the histopathological technique of microdissection and polymerase chain reaction (PCR) for the diagnosis of delayed postoperative endophthalmitis.

\section{Case report}

A 78 year old man with a history of vitreous floaters, a coronary bypass, and aortic valve replacement underwent an uncomplicated cataract extraction with intraocular lens (IOL) implantation in the right eye. Three months later, he developed increasing floaters in the right eye and was diagnosed with vitritis unresponsive to corticosteroid treatment. Examination revealed acuities of 20/25 in the right eye and 20/20 in the left with normal intraocular pressures. The right eye was significant for no anterior chamber cells or flare, dilated iris vessels, an IOL without deposits, 3+ vitreous cells with trace haze and peripheral pigmentary degeneration. The left eye was normal with the exception of trace vitreous cells and a choroidal naevus. A diagnostic vitrectomy was performed in the right eye. A portion of the vitreous specimen was cultured for fungi, aerobic and anaerobic bacteria, and the remainder was processed for cytopathological examination. All cultures for micro-organisms were negative.

The vitreous supernatant and unstained cytology slides were sent to the National Eye Institute for further evaluation. Vitreal analysis for interleukin 2 (IL-2), IL-4, IL-6, IL-10, IFN- $\gamma$, and TNF- $\alpha$ using ELISA (Endogen, Woburn, MA, USA) revealed undetectable cytokine levels. The vitreous slides were stained with Giemsa, Gram, and immunohistochemical stains for T cells, B cells, and macrophages. Cytopathological examination showed clusters of macrophages admixed with CD4+ and CD8+ T cells and B cells (Fig 1A). Gram positive bacilli were seen in the cytoplasm of a few macrophages (Fig 1B). The engulfed bacilli were microdissected under a microscope with a 30 gauge needle and submitted for PCR. ${ }^{1}$ Nested PCR with $P$ acnes specific oligodeoxynucleotide primers complementary to regions of 16S rDNA was used. $^{2}$ The primers were Pal, AAG GCC CTG CTT TTG TGG; rPa2, TCC ATC CGC AAC CGC CGA A; and rPa3, ACT CAC GCT TCG TCA CAG. Nested-PCR analysis revealed $P$ acnes (Fig 2). A diagnosis of delayed postoperative endophthalmitis was made.

\section{Comment}

The most common causes of vitritis in elderly patients are acquired or postoperative infections, sarcoidosis, and intraocular malignancies masquerading as uveitis. ${ }^{3}$ An early diagnostic procedure is indicated if postoperative endophthalmitis is suspected. In this case, although the chronic inflammation and intracytoplasmic Gram positive bacilli in a few macrophages suggested an infectious process, the negative cultures precluded the diagnosis of an infectious endophthalmitis. To further investigate the possibility of a bacterial infection nested PCR was performed on the micro-
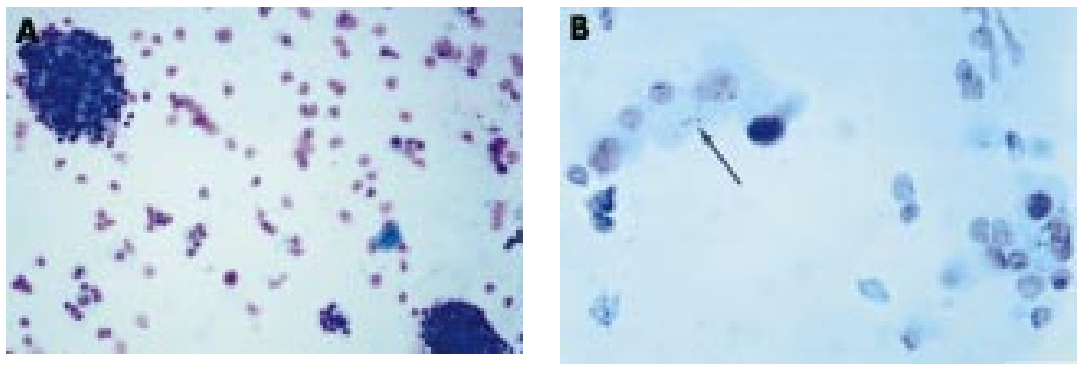

Figure 1 (A) Photomicrograph of the vitreous specimen showing clusters of macrophages admixed with T and B lymphocytes. Many degenerated lymphocytes were also present. (Giemsa, $\times 200$ ). (B) Higher power photomicrograph of the vitreous specimen showing Gram positive pleomorphic bacilli (arrow) in the cytoplasm of a few macrophages (Gram stain $\times 640$ ).

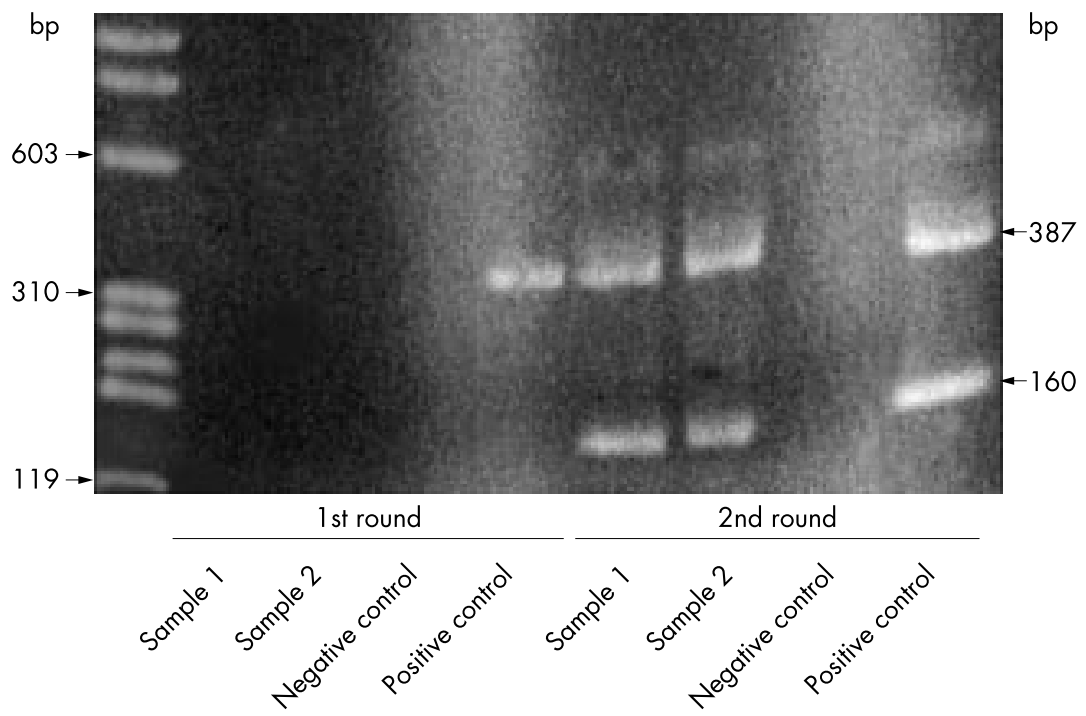

Figure 2 Nested PCR products of the microdissected bacilli from the vitreous specimen. The first round used $\mathrm{Pal}$ and $\mathrm{rPa} 2$. The second round used $\mathrm{Pal}$ and $\mathrm{rPa} 3$. The negative control in both rounds contained no DNA. The positive control in both rounds was $P$ acnes. 
negative delayed onset endophthalmitis. It also describes for the first time microdissection and PCR for the evaluation of endophthalmitis. Advantages of this technique are that it allows for a more comprehensive pathological examination on a limited specimen and provides the option of having the molecular studies being performed elsewhere.

R R Buggage, D F Shen, C-C Chan Laboratory of Immunology, National Eye Institute, National Institutes of Health, Bethesda, MD, USA

D G Callanan

Texas Retina Associates, Arlington, TX, USA

Correspondence to: Ronald R Buggage, MD, $\mathrm{NIH} / \mathrm{NEI}$, Building 10, Room 10N1 12, Bethesda, MD 20892-1857, USA; buggager@nei.nih.gov

Accepted for publication 21 January 2003

\section{References}

1 Zhuang Z, Bertheau P, Emmert-Buck MR, et al. A microdissection technique for archival DNA analysis of specific cell populations in lesions $<1 \mathrm{~mm}$ in size. Am J Pathol 1995:93:10595-9.

2 Hykin PG, Tobal K, Mclntyre G, et al. The diagnosis of delayed post-operative endophthalmitis by polymerase chain reaction of bacterial DNA in vitreous samples. J Med Microbiol 1994;40:408-15.

3 Berrocal AM, Davis Jl. Uveitis following intraocular surgery. Ophthalmol Clin North Am 2002; 15:357-64.

4 Lohmann CP, Linde HJ, Reischl U. Improved detection of microorganisms by polymerase chain reaction in delayed endophthalmitis after cataract surgery. Ophthalmology 2000;107: 1047-51; discussion 1051-2.

5 Aldave AJ, Stein JD, Deramo VA, et al. Treatments strategies for postoperative Propionibacterium acnes endophthalmitis. Ophthalmology 1999; 106:2395-401.

6 Buggage RR, Whitcup SM, Nussenblatt RB, et al. Using interleukin 10 to interleukin 6 ratio to distinguish primary intraocular lymphoma and uveitis. Invest Ophthalmol Vis Sci 1999;40:2462-3.

\section{Interferon treatment of childhood conjunctival lymphoma}

Mucosa associated lymphoid tissue (MALT) lymphoma is the most common ocular adnexal lymphoid proliferation. These neoplastic lesions have a more indolent course than non-MALT lymphomas, are usually found in the older age groups (50-70 years), are usually limited to localised (stage I) disease at presentation, and radiotherapy and chemotherapy have been the mainstay of treatment. $^{1}$

\section{Case report}

A 15 year old male was referred by an ophthalmologist after an 8 month history of unusual painless follicles at both nasal fornices (Fig lA). There were no visual symptoms and, based on a working diagnosis of an atypical vernal reaction, topical steroid treatment had resulted in mild size reduction of the lesions. Incisional biopsy was performed after the lesions remained static for 3-4 months.

The patient's visual acuity was $6 / 4$ in both eyes and intraocular pressures measured 15 $\mathrm{mm} \mathrm{Hg}$ in each eye. Slit lamp examination demonstrated small follicular deposits in both nasal fornices and nasal palpebral conjunctiva. The rest of the ocular examination was unremarkable. Review of systems was negative and the patient's past medical history and family medical history did not reveal the
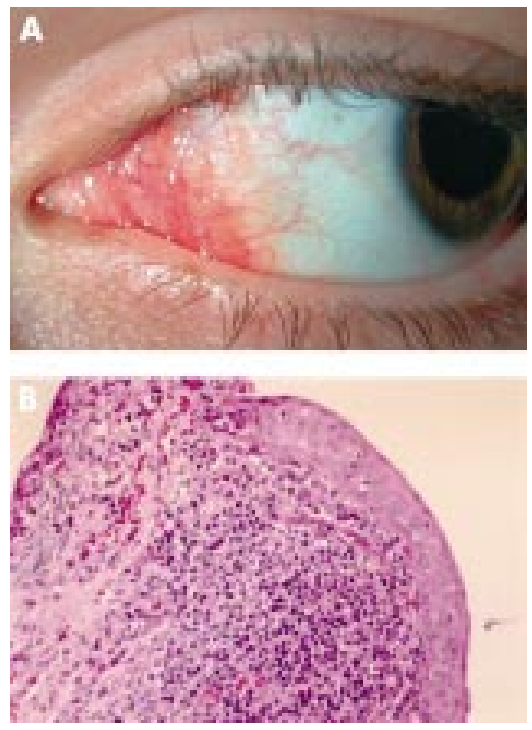

$\begin{array}{ll}\text { Figure } 1 & \text { (A) Conjunctival MALT }\end{array}$

lymphoma, nasal fornix of left eye. (B)

Histological section of conjunctival mucosa

demonstrating dense lymphoid infiltrate

(haematoxylin and eosin, original

magnification $\times 200$ ).

presence of lymphoproliferative or autoimmune diseases. There were no findings suggestive of Sjögren's syndrome and physical examination was normal.

The limited amount of biopsy tissue was divided for routine processing and flow cytometry; frozen tissue was therefore unavailable. Histologically a dense lymphoid infiltrate including benign appearing lymphoid follicles was identified (Fig 1B). Lymphoid follicles were surrounded by centrocytic-like cells and small lymphocytes, some of which infiltrated the conjunctival epithelium. Flow cytometry identified a monoclonal B cell population with a CD5-, CD20+, CD10 equivocal phenotype. The histopathological findings in isolation may have represented either an early marginal zone lymphoma or a benign B cell follicular hyperplasia. Absolute distinction on the small amount of tissue was not possible. However, in conjunction with the flow cytometric finding of a monoclonal B cell population, a diagnosis of low grade B cell lymphoma (probably of MALT type) could be made.

Systemic disease was excluded after the following investigations: lumbar puncture; bone marrow aspirate and trephine; CT chest, abdomen, pelvis and sinuses; gallium scan. The patient was subsequently treated with 10 intralesional injections of $10 \times 10^{6} \mathrm{IU}$ of interferon alfa (IFN- $\alpha$ ) over a 4 week period; no side effects were noted during this time. Complete resolution was achieved at 2 months, with no sign of recurrence after 18 months follow up.

\section{Comment}

Conjunctival lymphoma is mostly a disease of the elderly, with Shields et al reporting a mean age of diagnosis of 61 years. ${ }^{2}$ While not a common disease, Akpek et al suggest that its prevalence is higher than previously recognised, and that vigilance is required in patients with chronic ocular irritation and conjunctivitis who do not respond to conventional therapy. ${ }^{3}$ This is the youngest case of conjunctival lymphoma that we know of in the literature; hence conjunctival lymphoma should be considered in the differential diagnosis of atypical conjunctival lesions in younger patients.

Treatments outlined by Shields et al included radiotherapy $(44 \%)$, complete excisional biopsy (36\%), observation (9\%), chemotherapy $(6 \%)$, and cryotherapy $(4 \%){ }^{2}$

Radiotherapy has been widely used with successful results ${ }^{3-6}$ but ocular morbidity in the form of corneal ulcer, radiation induced cataract and ocular lubrication disorders have been reported. ${ }^{4}{ }^{7}$ Intralesional IFN- $\alpha$ is a relatively new therapy which has been shown to be both effective and safe in a small number of cases. ${ }^{1589}$ Non-sight threatening ocular complications such as subconjunctival haemorrhage and local chemosis have been reported, as well as minor transient systemic effects including headaches, nausea, fevers, chills, and myalgia. ${ }^{5}$ Administration of intralesional IFN- $\alpha$ is also a relatively simple and quick procedure. It shows great promise as a first line agent to treat conjunctival lymphoma, but long term follow up is needed.

\section{R S Lucas}

Department of Ophthalmology, Royal Brisbane Hospital, Herston, Queensland 4029, Australia

R Mortimore

Queensland Medical Laboratory Consulting Pathologists, 60 Ferry Road, West End,
Queensland 4101, Australia

T J Sullivan Department of Ophthalmology, Royal Brisbane Hospital, Herston, Queensland 4029, Australia

$M$ Waldie Department of Ophthalmology, Royal Brisbane Hospital, Herston, Queensland 4029, Australia

Correspondence to: Associate Professor Timothy John Sullivan, Eyelid, Lacrimal and Orbital Clinic, Department of Ophthalmology, Royal Brisbane Hospital, Herston, Queensland 4029, Australia; tis@gil.com.au

Accepted for publication 22 January 2003

\section{References}

1 Blasi MA, Gherlinzoni F, Calvisi G, et al. Local chemotherapy with interferon- $\alpha$ for conjunctival mucosa-associated lymphoid tissue lymphoma. Ophthalmology 2001;108:559-62.

2 Shields CL, Shields JA, Carvalho C, et al. Conjunctival lymphoid tumours. Clinical analysis of 117 cases and relationship to systemic lymphoma. Ophthalmology 2001;108:979-84.

3 Akpek EK, Polcharoen W, Ferry JA, et al. Conjunctival lymphoma masquerading as chronic conjunctivitis. Ophthalmology 1999; 106:757-60

4 Heuring $\mathbf{A H}$, Franke FE, Hütz WW Conjunctival CD5+ MALT lymphoma. Br J Ophthalmol 2001;85:498-9.

5 Cahill MT, Moriarty PA, Kennedy SM. Conjunctival "MALToma" with systemic recurrence. Arch Ophthalmol 1998;

116:97-9.

6 Scullica L, Manganelli C, Turco S, et al. Bilateral non-Hodgkin lymphoma of the conjunctiva. Eye 1999; 13:379-80.

7 Bessel EM, Henk JM, Whitelocke JF, et al. Ocular morbidity after radiotherapy of orbital and conjunctival lymphoma. Eye 1987; 1:90-6.

8 Lachapelle KR, Rathee R, Kratky V, et al. Treatment of conjunctival mucosa-associated lymphoid tissue lymphoma with intralesional injection of interferon alfa-2b. Arch Ophthalmol 2000; 1 18:284-5

9 Cellini M, Possati GL, Puddu P, et al. Interferon alpha in the therapy of conjunctival lymphoma in an HIV+ patient. Eur J Ophthalmol 1996;6:475-7. 


\section{Unilateral corneal anaesthesia and ulceration following squint surgery in a child with Pendred syndrome and bilateral sixth nerve palsy}

We present a 4 year old child with Pendred syndrome and bilateral sixth nerve palsy. To our knowledge this association has not been previously reported. In addition, this patient developed unilateral corneal ulceration with associated corneal anaesthesia following squint surgery. We will discuss the pathophysiology of this unusual complication following squint surgery.

\section{Case report}

This patient presented when he was 6 month old with right convergent squint. He was diagnosed with Pendred syndrome (sensorineural hearing loss and thyroid dysfunction) by the paediatricians and the otolaryn gologists following abnormal thyroid function tests and a computed tomograph (CT) scan of the temporal bones showing Mondini malformations of both cochleas. At presentation his visual acuities were 6/60 right eye and 6/36 left eye using the Cardiff acuity cards. He had bilateral alternating esotropia with an inability to abduct either eye. There was no globe retraction or abnormal lid movements and a magnetic resonance imaging (MRI) scan had shown congenital absence of the auditory nerves but no other abnormality. A diagnosis of bilateral sixth nerve palsy was made. The squint was cosmetically poor and measured at 45 prism dioptres in the distance and near. $\mathrm{He}$ had low hypermetropia with no significant anisometropia. Funduscopy was normal. He was reviewed regularly in the paediatric eye clinic over the next 3 years during which time his visual acuities were within normal limits, the best recorded acuity being 6/9 right eye and 6/9 left eye using singles.

When he was 4 years old, he underwent bilateral superior rectus and inferior rectus lateral transpositions under general anaesthesia, which was uneventful with no immediate postoperative complications, and a cosmetically acceptable alternating convergent squint of 15 prism dioptres for distance and near.

Two months later he developed a left inferior corneal ulcer (Fig l) with surrounding punctate epitheliopathy which surprisingly did not seem to cause him as much distress as expected. The left corneal sensation was definitely reduced compared to the right which appeared normal. Sensation was as sessed clinically (an anaesthesiometer was not available), and was consistently reproducible by different ophthalmologists. There was no exophthalmos or any other sign of thyroid orbitopathy. The right eye remained asymptomatic. Empirical therapy with topical

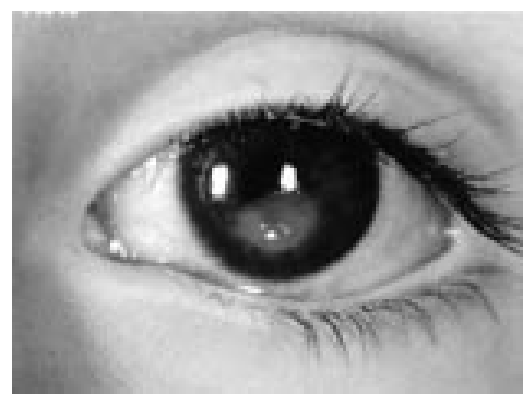

Figure 1 Inferior corneal ulcer before treatment. ofloxacin and lubricants was unhelpful. He proceeded to have glue tarsorrhaphy which transiently aided the healing of the corneal ulcer. However, the ulcer quickly recurred when the tarsorrhaphy reversed. He subsequently had left inferior lid shortening with a canthal sling to elevate the lower lid to protect the corneal epithelium. The ulcer resolved leaving an area of corneal scarring. He is being reviewed regularly in the eye clinic.

\section{Comment}

Pendred syndrome is an autosomal recessive disorder characterised by congenital deafness and thyroid goitre. The hearing loss is usually severe and is present at birth, and the goitre generally appears at puberty or later but may be present in early childhood with an associated euthyroid or hypothyroid state. ${ }^{1-4}$ Affected individuals are reported to be otherwise normal.

The pathophysiology of the corneal anaesthesia and ulceration in this patient is uncertain. There are several possible reasons for the corneal anaesthesia. They include herpes simplex keratitis, postoperative anterior segment ischaemia, surgical trauma to the long posterior ciliary nerves or ciliary ganglion, congenital absence of sensation, and surgery reducing Bell's phenomenon.

The clinical course was not typical of herpes simplex and there was no previous history of corneal pathology. Postoperative anterior ischaemic syndrome was unlikely as only two recti muscles were operated on and no anterior uveitis was observed. To our knowledge there are no reported cases of corneal anaesthesia after squint surgery. There was no evidence of pupillary involvement, which one may expect with trauma to the long posterior ciliary nerves or ciliary ganglion.

Congenital absence of corneal sensation was the most likely cause, especially in view of his unusual cranial nerve anomalies, and we believe he had pre-existing corneal anaesthesia before squint surgery despite the absence of any other fifth cranial nerve signs. Following the lateral transposition of the superior rectus his Bell's phenomenon was noted to be absent thereby compromising his corneal protection. In addition, he was observed to have significant lagophthalmos while asleep. We believe that the combination of corneal anaesthesia, abolished Bell's phenomenon, and lagophthalmos compromised his corneal integrity resulting in corneal ulceration.

This case highlights the importance of determining corneal sensation before transposition surgery on the superior rectus as Bell's phenomenon may be abolished therefore compromising corneal protection. This is especially relevant in patients with unusual cranial neuropathy and lagophthalmos.

R V Wintle

Eye Unit, Southampton General Hospital, Tremona Road, Southampton SO22 5DS, UK

Y F Choong

Eye Unit, University Hospital of Wales, Cardiff, UK

D E Laws

Department of Ophthalmology, Singleton Hospital, Swansea, UK

Correspondence to: Mr Richard V Wintle, Eye Unit Southampton General Hospital, Tremona Road, Southampton SO22 5DS, UK ; richardwintle67@yahoo.com

Accepted for publication 16 February 2003

\section{References}

1 Pendred V. Deaf mutism and goitre. Lancet $1896 ; 11: 532$.
2 Reardon W Trembath RC. Pendred syndrome. J Med Genet 1996;33:1037-40.

3 Reardon W, Coffey R, Phelps PD, et al. Pendred syndrome -100 years of underascertainment? $Q$ J Med 1997;90:443-7.

4 Fraser GR. Association of congenital deafness with goitre (Pendred's syndrome): a study of 207 families. Ann Hum Genet 1965;28:201-49.

\section{Gemella haemolysans acute} postoperative endophthalmitis

Endophthalmitis is perhaps the most feared complication of cataract surgery, with a reported incidence between $0.07 \%$ and $0.13 \% .^{12}$ The most common organisms reported in previous studies are Gram positive staphylococci and streptococci. ${ }^{34}$ We report a case of severe endophthalmitis with an unusual Gram positive organism, after uncomplicated phacoemulsification, with foldable intraocular lens implantation.

\section{Case report}

A 66 year old white man underwent routine phacoemulsification cataract extraction with posterior chamber lens implantation (Acrylic, Model Hydroview H60M, Bausch \& Lomb) to the right eye in January 2002

The left eye had previously undergone similar surgery in September 2001. He was generally in good health, and on no medication. There was a past medical history of sarcoidosis treated with oral prednisolone in 1970, which has since been in remission, and an episode of staphylococcal septicaemia in 1987, without sequelae.

On the first postoperative day, visual acuity measured 6/9 unaided and ocular examination was unremarkable. That same afternoon the patient developed ocular pain, initially relieved by paracetamol (acetaminophen), which however, worsened during the night with progressive deterioration of vision. He presented to the ophthalmic emergency department the following morning with the aforementioned symptoms. Visual acuity was reduced to hand movements right eye and 6/9 left eye. Slit lamp examination revealed an oedematous cornea with Descemet's folds. The anterior chamber was hazy, with $1 \mathrm{~mm}$ hypopyon and the intraocular pressure measured $38 \mathrm{~mm} \mathrm{Hg}$.

There was no red reflex. B-scan ultrasound examination showed extensive vitreous debris with attached retina. The left eye was pseudophakic with no abnormalities of note. A diagnosis of acute postoperative endophthalmitis was made. Anterior chamber and vitreous samples were obtained for aerobic and anaerobic culture/sensitivity and Gram staining. Intravitreal vancomycin $2 \mathrm{mg}$ and amikacin $300 \mu \mathrm{g}$, each in $0.1 \mathrm{ml}$ of balanced salt solution and subconjunctival cefuroxime 125 mg were administered. Oral ciprofloxacin 500 $\mathrm{mg}$ twice daily, prednisolone $60 \mathrm{mg}$ once a day, topical gentamicin hourly, ofloxacin hourly, and atropine $1 \%$ twice a day were commenced

Preliminary Gram staining suggested a Gram positive coccus, sensitive to ciprofloxacin-oral and topical antibiotics were therefore continued. Owing to difficulty in identifying the nature of the organism, the samples were sent to a regional reference laboratory, which identified Gemella haemolysans from both anterior chamber and vitreous aspirates. The organism was reported to be sensitive to gentamicin, ciprofloxacin, laevofloxacin, amoxicillin/clavulanate, chloromycetin, and resistant to trimethoprim. 
The patient continued to make steady progress; 2 months later vision had improved to $6 / 9$ unaided. The patient at that time was troubled by floaters secondary to considerable vitreous debris. At last review in September 2002 , visual acuity had further improved to $6 / 4$ with $-0.75 \mathrm{DSph}$ correction.

\section{Comment}

Gemella haemolysans is an aerobic or facultative anaerobic, Gram positive coccus, a normal commensal of the oral cavity and upper respiratory tract of low virulence. ${ }^{56}$ Systemic infection may lead to septic shock, meningitis, arthritis, or pneumonia, all of which are rare Identification is difficult. Though Gram positive, the cocci are easily decolorised and hence may appear Gram variable or even negative.

Initially Gemella was included under the genus Neisseria but is now classified as separate genus within the family Streptococcacea. ${ }^{7}$ No studies on susceptibility to antiseptics have been published, though there is no reason to believe that it may be resistant to povidone-iodine preparations. The organism is susceptible in vitro to penicillin streptomycin, vancomycin, chloramphenicol and tetrasulphathiazole.

A literature search revealed only one previously reported case of infection by Gemella haemolysans, with keratitis and consecutive endophthalmitis. ${ }^{6}$ Interestingly this patient was reported to have active sarcoidosis on systemic steroid therapy, whereas our patien had a past history of sarcoidosis. This possible association between sarcoidosis and infection by Gemella may be purely coincidental, as no such association has been reported with systemic infection.

Gemella haemolysans is difficult to identify, because of its close resemblance to viridans streptococcus and Neisseria. As diagnostic technology improves, Gemella haemolysans endophthalmitis may be described more often in the future. This report highlights the importance of infection with rare commensal organisms in healthy, immunocompetent individuals after uneventful phacoemulsification cataract surgery.

S V Raman, N Evans, T J Freegard

Royal Eye Infirmary, Apsley Road, Plymouth, UK

R Cunningham

Department of Microbiology, Derriford Hospital Plymouth, UK

Correspondence to: S V Raman, West of England Eye Unit, Royal Devon and Exeter Hospital, Exeter, UK; Vasant317@yahoo.com

Accepted for publication 25 February 2003

\section{References}

1 Aaberg TM Jr, Flynn HW Jr, Schiffman J, et al. Nosocomial acute-onset postoperative survey; a ten-year review of incidence and outcomes. Ophthalmology 1998;105:100410.

2 Javitt JC, Vitale S, Canner JK, et al. National outcomes of cataract extraction; endophthalmitis following inpatient surgery. Arch Ophthalmol 1991;109:1085-9.

3 Shrader KS, Band JD, Lauter CB, et al. The clinical spectrum of endophthalmitis; incidence, predisposing factors, and features influencing outcome. J Infect Dis $1990 ; 162: 115-20$

4 The Endophthalmitis Vitrectomy Study Group. Results of the endophthalmitis vitrectomy study; a randomised trial of immediate vitrectomy and of intravenous antibiotics for the treatment of postoperative bacterial endophthalmitis. Arch Ophthalmol 1995,$113 ; 1479-96$.
5 Fresard A, Michael VP, Rueda X, et al. Gemella haemolysans endocarditis. Clin Infect Dis 1993; 16;586-7.

6 Ritterband D, Shah M, Kresloff $M$, et al. Gemella haemolysan keratitis and consecutive endophthalmitis. Am J Ophthalmol 2002;133:268-9

7 Klipper-Balz R, Schleifer KH. Transfer of Streptococcus morbillorum to the Gemella genus, Gemella morbillorum comb nov. Int $J$ Syst Bacteriol 1988;38:442-3.

\section{Does topical brimonidine tartrate help NAION?}

There is no proved treatment for non-arteritic anterior ischaemic optic neuropathy (NAION). Topical brimonidine tartrate has been reported to have a neuroprotective benefit for retinal ganglion cells following experimental elevation of intraocular pressure and optic nerve injury in the rat, which is blocked with coadministration of the $\alpha$-2 antagonist, rauwalscine. ${ }^{1-3}$ Increased retinal ganglion cell survival has also been shown to occur following oral administration of brimonidine in monkeys with experimental glaucoma. ${ }^{4}$ These results were the basis of the recently aborted clinical trial of topical brimonidine purite for acute NAION and our retrospective study of 31 patients with NAION, who were evaluated within 3 weeks of the onset of visual loss and had follow up for a minimum of 8 weeks. During 2001-2, we treated all (14) patients with brimonidine tartrate within 14 days (mean 5.5, SD 5.52) of the onset of visual loss. Five patients were treated after 1 day of symptoms. The drops were taken four times a day in 11 , three times a day in one, and twice a day in two patients. All (17) untreated patients were evaluated the year before and were matched to the treated group for age, sex, cardiovascular risk factors, previous aspirin use, and previous first eye NAION

Snellen visual acuity and colour vision, using the Ishihara colour plates, were documented and expressed as a decimal equivalent (for acuity: $20 / 60=0.33$ and light perception $=0.001$; for colour vision: the number of correctly identified plates/the total number of plates). The visual fields (Humphrey or tangent perimetry) were analysed and defects were graded according to the following scale: $0=$ normal, $1=$ arcuate nerve fibre bundle defects, $2=$ relative central $(<6$ degrees $)$ caecocentral or altitudinal defects, $3=$ altitudinal defect plus additional loss, $4=$ no light perception. A third examiner, who was unaware of the dates of the visual fields and the patients' treatment status, also evaluated all visual fields and determined, in each patient, whether the field was better or worse than or equivalent to the other field. The intraocular pressure was normal in all except two patients. The pressure was $23 \mathrm{~mm} \mathrm{Hg}$ in one patient in the treated group and $24 \mathrm{~mm} \mathrm{Hg}$ in one patient in the untreated group.

Statistical analysis of the data involving comparisons of the treated and untreated groups at baseline and 8-12 weeks was performed using the two tailed $t$ test. ${ }^{5}$ The Wilcoxon signed rank test was used to compare the individual vision performance from baseline to the 8-12 week examination. For visual acuity and colour vision, a positive rank indicated improvement and a negative rank indicated a worse visual outcome. For the visual field grade, the scale was reversed. Spearman correlation analysis was performed on the time to start therapy and whether worsening in any visual parameter occurred.

The mean baseline acuity (0.56, SD 0.30 ) and visual field (1.9, SD 0.73) for the treated group was similar to the acuity $(0.40$, SD 0.41 $\mathrm{p}=0.22)$ and field (1.9, SD 0.75; $\mathrm{p}=0.96)$ fo controls. The mean baseline colour vision (0.74, SD 0.4) for the treated group was higher than the colour vision $(0.45, \mathrm{SD} 0.44)$ for controls, but the difference was not significant $(\mathrm{p}=0.07)$. At the $8-12$ week examination, the mean visual acuity was 0.29 (SD 0.30 ) for treated and 0.49 (SD 0.39; $p=0.12$ ) for untreated patients. The mean visual field grade was 2.2 (SD 0.81 ) for treated and 1.62 (SD 0.70; $\mathrm{p}=0.04$ ) for untreated patients. The mean colour vision was 0.42 (SD 0.41) for treated and 0.55 (SD 0.46; $\mathrm{p}=0.43$ ) for untreated patients.

For the masked examiner's evaluation, the mean baseline visual field (2.0, SD 0.91) was similar to the field (1.93, SD $0.96 ; p=0.85$ ) for controls. At the 8-12 week examination, the mean visual field grade was 2.15 (SD 0.99) for treated and 1.87 (SD 0.92; $\mathrm{p}=0.43$ ) for untreated patients. This examiner further found that the outcome visual fields for the treated group were improved in two patients, worse in six patients $(50 \%)$, and unchanged in four patients. The outcome visual fields for the control group were improved in five patients, worse in two patients (13\%), and unchanged in eight patients.

The Wilcoxon signed rank analysis demonstrated that for visual acuity, two patients in the control group and 10 patients in the treated group had negative values or a worse outcome at $8-12$ weeks $(p=0.007)$. For colour vision, one patient in the control group and eight patients in the treated group had negative values or a worse outcome $(p=0.013)$. For visual fields, one patient in the control group and four patients in the treated group had positive values or a worse outcome at $8-12$ weeks $(p=0.046)$.

The average time to start the drops was 3.5 days from the onset of visual loss in those patients who worsened. There was no correlation with a worse outcome and time to initiate therapy.

For all parameters of vision testing, there was a trend for worse visual performance at 8-12 weeks in the group treated with topical brimonidine. Although there was no significant difference for the colour vision outcome, this might reflect that the baseline colour vision value was better for the treated group. The outcome visual field grade was significantly worse in the treated group. The masked examiner's visual field evaluations demonstrated that more treated patients worsened than in the untreated group. When the baseline and outcome of all visual parameters for each individual were compared, the treated group had a significantly worse outcome at 8-12 weeks.

Our results are not the first description of worse outcome in patients treated with $\alpha-2$ agonists for central nervous system ischaemic disease. Studies in animal models and clinical studies in humans suggest that certain classes of drugs, including $\alpha-2$ receptor agonists, may impede recovery following stroke. Clonidine administration caused recurrence of the neurological deficit in animals who had initially recovered. In a retrospective clinical study, the level of motor recovery of stroke patients was worse in those treated with $\alpha-2$ agonists than in patients not receiving these agents. $^{8}$

Although in experimental optic nerve injury in animal models, brimonidine appears to offer neuroprotection, our results demonstrate that brimonidine tartrate, applied topically up to four times daily, does not appear to be a beneficial treatment for acute NAION. It 
is possible earlier treatment might have been more effective, although patients who worsened received treatment sooner than those who did not worsen. Increased dosing frequency or using a different preparation of brimonidine might be more effective. Additionally, the number of subjects in the study was small and a negative trend could appear more profound.

H E Fazzone, M J Kupersmith The Institute for Neurology and Neurosurgery, Beth Israel Medical Center, the New York Eye and Ear Infirmary New York, USA

J Leibmann

The New York Eye and Ear Infirmary

Correspondence to: Mark J Kupersmith, MD, Department of Neuro-ophthalmology, Room 535, The Institute for Neurology and Neurosurgery, Beth Israel Medical Center, 170 East End Avenue, New

York, NY 10128, USA; mkuper@bethisraelny.org

Accepted for publication 2 March 2003

\section{References}

1 Woldemussie $E$, Ruiz $G$, Wijono $M$, et al. Neuroprotection of retinal ganglion cells by brimonidine in rats with laser-induced chronic ocular hypertension. Invest Ophthalmol Vis Sci 2001:42:2849-55

2 Wheeler LA, Woldemussie E. Alpha-2 adrenergic receptor agonists are neuroprotective in experimental models of glaucoma. Eur J Ophthalmol 2001;11/suppl 2):S30-5.

3 Yoles E, Wheeler LA, Schwartz M Alpha2-adrenoreceptor agonists are neuroprotective in a model of optic nerve degeneration. Invest Ophthalmol Vis Sci 1999:40:65-73.

4 Wheeler LA, Gil DW, Woldemussie E. Role of alpha-2 adrenergic receptors in neuroprotection and glaucoma. Surv Ophthalmol 2001;45(suppl 3):S290-4.

5 Fisher LD, Van Belle G. One- and two-sample inference. In: Biostatistics, a methodology for inference. In: Biostatistics, a methodology for
the health sciences. Ch 5. New York: John Wiley, 1993.146-7.

6 Fisher LD, Van Belle G. Nonparametric, distribution-free and permutation models: robust procedures. In: Biostatistics, a methodology for the health sciences. Ch 8. New York: John Wiley, 1993:310-14.

7 Fisher LD, Van Belle G. Association and prediction: linear models with one predictor variable. In: Biostatistics, a methodology for the health sciences. Ch 9. New York: John Wiley, 1993:385-6.

8 Goldstein LB. Potential effects of common drugs on stroke recovery. Arch Neurol 1998;55:454-6.

\section{Chronic eye movement induced pain and a possible role for its treatment with botulinum toxin}

Chronic ocular pain may have many causes and can be a frustrating problem for both patient and doctor alike. We describe two patients who had similar symptoms and eye findings who had been unable to relieve their pain with conventional analgesia. We postulate a cause for their pain and describe our experience of a treatment strategy using a standard dose of botulinum toxin injection into an extraocular muscles.

\section{Case 1}

A 56 year old white woman presented with what was initially thought to be a right orbital cellulitis but investigations and clinical course subsequently suggested a non-infectious idiopathic inflammatory aetiology. Her history suggested orbital myositis and she described right sided facial weakness, nausea, and right sided ptosis. She had a 9 month course of oral steroids and despite this needed tramadol, paracetamol, and flurbiprofen to control her pain. Her symptoms and examination findings slowly stabilised until she was left with marked limitation of upgaze in her right eye. Her symptoms did not change over the next 3 years, at which point she was referred to our care. When she attempted to look up she described a juddering sensation and severe pain just above the eye. She rarely had pain at night but was still using regular oral ibuprofen for pain relief. Her pain was exacerbated by reading or looking at the computer and she complained of vertical diplopia.

On examination she had limitation of abduction and elevation of her right eye and prisms did not improve her symptoms. A tentative diagnosis of inflammatory spasm was made. She was treated with botulinum toxin injection to her right inferior rectus. Two weeks later there was much less tightness and discomfort in the orbit but she had diplopia in all positions of gaze and was forced to occlude one eye. Three months later the pain was much improved but she still found the diplopia intolerable and declined further treatment.

\section{Case 2}

A 46 year old white man presented complaining of chronic constant ocular discomfort which followed strabismus surgery 8 years earlier for an A-pattern exotropia with diplopia on downgaze. The pain was worsened by prolonged television watching and prisms in his glasses did not help. Pain was much worse on upgaze and right gaze, which were limited. Oral non-steroidal anti-inflammatory agents (NSAIDs) did reduce the pain a little but only when taken in high doses ( $100 \mathrm{mg}$ three times daily flurbiprofen).

On examination he had a right hyperphoria, with an A-pattern esotropia and an abnormal head posture for distance. He still had diplopia. Botulinum toxin was injected into his left medial rectus muscle, which resulted in a profound reduction in his symptoms, leaving him with a small exophoria. His diplopia resolved completely after 10 weeks. The "pressure sensation" and pain in the right eye recurred after about 6 months, this time with no diplopia. He had a further injection of toxin 8 months after the first which again significantly improved his pain but gave him diplopia for 3 weeks. He continues to take flurbiprofen $50 \mathrm{mg}$ three times daily orally.

\section{Comment}

The pain demonstrated by these two patients is typically much worse in certain directions of gaze and particularly during prolonged gaze holding such as when reading or watching television. It had a clear precipitating event and the most remarkable feature is that it had persisted for over 2 years in each case without significant progression or regression. No active disease process could be found to account for the continued pain. The pain is severe and responds only to high doses of analgesics, particularly NSAIDs. None of our patients felt that their pain was satisfactorily controlled by their analgesics.

We believe that there may be a process of chronic low grade inflammation affecting the extraocular muscles or the tissues around them which is exacerbated by continued contraction and relaxation of the same muscles. Muscular spasm perhaps triggered by this inflammatory process may be the cause of the most severe pain and this could account for the exacerbations of pain in certain directions of gaze and on prolonged gaze holding activities. Ocular muscle ischaemia, perhaps caused by constricting scar tissue, remains a possibility but the onset of the pain is very fast making this less likely.

The pain relief seen in our patients may simply be the result of paralysing an inflamed muscle but there is growing evidence for a separate antinociceptive effect of botulinum toxin. ${ }^{1}$ No direct peripheral cutaneous antinociceptive effect could be shown by Blersch et $\mathrm{al}^{2}$; however inhibition of release of substance $\mathrm{P}$ has been demonstrated in vitro and it can be hypothesised that botulinum toxin treatment may reduce the local release of nociceptive neuropeptides from either cholinergic neurons or from $\mathrm{C}$ or A delta fibres in vivo. ${ }^{3}$ The mechanisms by which botulinum toxin may relieve pain, including a possible analgesic effect of botulinum toxin metabolites, are reviewed by Guyer. ${ }^{4}$

There is a growing literature on the use of botulinum for painful conditions, ${ }^{5}$ particularly those in which muscle spasm plays a part. These include writer's cramp, ${ }^{6}$ postoperative pain in spastic cerebral palsy, ${ }^{7}$ and perhaps more surprisingly migraine ${ }^{8}$ and painful tic convulsif.' Many of the reported uses are single case studies and not all controlled trials have shown a positive effect of treatment. ${ }^{10}$

It is not possible to rule out a powerful placebo effect in our patients but, whatever the mechanism of action, their pain was vastly improved and botulinum toxin treatment is very safe in competent hands.

In the cases described botulinum toxin served a dual purpose in that it had the potential to improve their ocular deviation for which it is well known and it also reduced the severe ocular discomfort. Unfortunately, the resulting diplopia limited its usefulness in one case but we feel that this treatment should be considered in this unusual group of patients who present a difficult management problem even to the most experienced ophthalmologists.

B J L Burton, S R Khan, J P Lee Moorfields Eye Hospital, City Road, London, UK Correspondence to: John P Lee, Moorfields Eye Hospital, City Road, London, UK; john.lee@moorfields.nhs.uk

Accepted for publication 5 March 2003

\section{References}

1 Sheean G. Botulinum toxin for the treatment of musculoskeletal pain and spasm. Curr Pain Headache Rep 2002;6:460-9.

2 Blersch W, Schulte-Mattler WJ, Przywara S, et al. Botulinum toxin $A$ and the cutaneous nociception in humans: a prospective, double-blind, placebo-controlled, randomized study. J Neurol Sci 2002;205:59-63.

3 Aoki KR. Pharmacology and immunology of botulinum toxin serotypes. J Neurol 2001;248(Suppl 1):3-10.

4 Guyer BM. Mechanism of botulinum toxin in the relief of chronic pain. Curr Rev Pain 1999;3:427-31.

5 Jost WH, Kohl A. Botulinum toxin: evidence-based medicine criteria in rare indications. J Neurol $2001 ; \mathbf{2 4 8}$ (Suppl 1):39-44.

6 Turjanski N, Pirtosek Z, Quirk J, et al. Botulinum toxin in the treatment of writer's cramp. Clin Neuropharmacol 1996;19:314-20.

7 Barwood S, Baillieu C, Boyd R, et al. Analgesic effects of botulinum toxin $A$ : a randomized, placebo-controlled clinical trial. Dev Med Child Neurol 2000;42: 1 16-21. 
8 Gobel H, Heinze A, Heinze-Kuhn K, et al. Evidence-based medicine:botulinum toxin $A$ in migraine and tension-type headache. J Neurol 2001;248(Suppl 1):34-38

9 Micheli F, Scorticati MC, Raina G. Beneficial effects of botulinum toxin type $A$ for patients with painful tic convulsif. Clin Neuropharmacol 2002;25:260-2

10 Wheeler AH, Goolkasian P, Gretz SS Botulinum toxin $\mathrm{A}$ for the treatment of chronic neck pain. Pain 2001;94:255-60.

\section{Intrastromal lamellar femtosecond laser keratoplasty with superficial flap}

Lamellar keratoplasty has usually been performed taking a trephine to delineate the extent of the tissue to be excised, and a knife or similar instrument to remove the lamellar corneal tissue from the underlying deep corneal bed. In a similar way, the lamellar donor tissue was prepared and inserted into the recipient bed. The depth of the lamellar excision extended from the corneal epithelial surface to the deep corneal stroma. Marked disadvantages of the technique have been pronounced corneal astigmatism and optical insufficiencies of the interface between the lamellar graft and the recipient corneal bed caused by irregularities of both surfaces. The purpose of the present report was to describe the new femtosecond laser technology, which may enable us to perform a new type of intrastromal lamellar keratoplasty with pres ervation of an intact Bowman's layer and regular corneal epithelium.

\section{Case report}

Using a corneal contact lens and a femtosecond laser (20/10 Perfect Vision, Am Taubenfeld 21/1, D-69123 Heidelberg, Germany) with a wavelength of $1060 \mathrm{~nm}$, a spot size of about $10 \mu \mathrm{m}$, and a laser pulse duration of several hundred femtoseconds, a pre-descemetal incision running parallel to the corneal surface was created in five postmortem eyes of slaughterhouse pigs. The diameter of the deep stromal incision was $7 \mathrm{~mm}$. In a second step, a circular sagittal incision was performed starting from the peripheral edge of the already existing incision in the predescemetal level to the superficial layer of the corneal stroma. In continuation of the latter sagittal incision, a corneal flap was prepared with a diameter of $7 \mathrm{~mm}$, a thickness of about $100 \mu \mathrm{m}$, a hinge, and three positional pikes. The pikes in the flap with the corresponding notches in the bed of the flap were formed to increase the rotational stability of the flap after repositioning. The height of the peaks was about $0.40 \mathrm{~mm}$. After opening of the flap the intrastromal segment situated between the pre-descemetal incision and the incision in the superficial stromal level was removed and exchanged against a similar formed segment obtained from another (donor) pig eye. In a final step, the flap was repositioned. For all eyes included in the study, the intrastromal corneal button and the superficial flap with the three positional pikes could be prepared without major difficulties. The corneal buttons could easily be repositioned into their original beds as well as into the recipient beds of other eyes in which the recipient beds were created with the same diameter as the donor button. The time taken for preparation of the intrastromal corneal button and the corneal flap, and for the exchange of the corneal buttons was less than 10 minutes in all cases.

\section{Comment}

Femtosecond laser technology allows a new type of intrastromal lamellar keratoplasty with removal of a mid-stromal segment and preservation of an intact Bowman's membrane. Considering the decreased amount of allogenic corneal tissue transplanted, and regarding the preservation of the original corneal surface, lamellar intrastromal femtosecond laser keratoplasty may be associated with a smaller rate of immunological graft reaction and with a lower postoperative corneal astigmatism in some eyes. Future clinical studies may show whether positional edges in the superficial flap increase its postoperative rotational stability.

Proprietary interest: none

Universitäts-Augenklinik, Theodor-Kutzer-Ufer 1-3, 68167 Mannheim, Germany Jost.Jonas@ma.augen.uni-heidelberg.de

Accepted for publication 17 March 2003

\section{References}

1 Stern D, Schoenlein RW, Puliafito CA, et al. Corneal ablation by nanosecond, picosecond, and femtosecond lasers at 532 and $625 \mathrm{~nm}$. Arch Ophthalmol 1989;107:587-92.

2 Krueger RR, Quantock A, Juhasz T, et al. Ultrastructure of picosecond laser intrastromal photodisruption. J Refract Surg 1996;12:607-12.

3 Kurtz RM, Horvath C, Liu HH, et al. Lamellar refractive surgery with scanned intrastromal picosecond and femtosecond laser pulses in animal eyes. J Refract Surg 1998;14:541-8.

4 Seitz B, Langenbucher A, Kus MM, et al Nonmechanical corneal trephination with the excimer laser improves outcome after penetrating keratoplasty. Ophthalmology 1999:106:1156-64; discussion 1165.

\section{Demographic study of paediatric allergic conjunctivitis within a multiethnic patient population}

From October 1999, all patients referred to the paediatric ophthalmology service in Bradford have been added to a computerised database. This is the only paediatric ophthalmology service within the city of Bradford and receives all GP referrals of this type. Patients with a clinical diagnosis of chronic allergic conjunctivitis were identified from October 1999 to July 2001. We compared the relative prevalence of chronic allergic eye disease between white and Asian patients in the paediatric population of the city of Bradford.

Confirmation of the diagnosis of chronic allergic conjunctivitis was made using case records. All patients were seen at the first visit by a consultant paediatric ophthalmologist (JAB).

A diagnosis of chronic allergic conjunctivitis was made if the patient had characteristic symptoms and signs based on criteria set out by Buckley in 1998. ${ }^{1}$ This was done to ensure accurate and consistent diagnosis of chronic allergic conjunctivitis so as not to include other forms of ocular allergy-for example, drug allergy or preservative toxicity. Inclusion criteria required a history of at least three of the following: a history of recurring symptoms over a period of at least 1 year; itching as a symptom; personal or family history of nonocular allergic disease; and exacerbation during the pollen season and/or exposure to household pets. Presence of the following clinical signs was also necessaryconjunctival hyperaemia and subtarsal papillae.

Patients were excluded if they had any signs of staphylococcal blepharoconjunctivitis such as eyelid and eyelash crusting; matting of the eyelids; purulent, sticky discharge; eyelid notching and scarring. Patients with mixed disease were also excluded from this study. The presence of corneal complications that required topical steroid for resolution was used to define severe disease.

Clinical dato

Forty three patients were identified from the database: 39 patients fulfilled entry criteria for this study and records were retrieved for 35. There were 24 Asians and 11 white children.

For Asian patients, the mean age was 9.58 (SD 4.02) years. For the white patients, the mean age was 7.82 (SD 3.19) years,. Follow up ranged from 3-14 months, mean 6 months The prevalence of allergic conjunctivitis in Asians was 59 per 100000 (24 in 40 524) and in white children, 12 per 100000 (11 in 93 398); a relative prevalence of 5 to 1 ( $\chi^{2}$ test $\mathrm{p}<0.001$ )

There was a predominance of males in both ethnic groups, 2.4:1 in Asians and 1.8:1 in white children. This difference in sex was not significant between both groups (Fisher's test, $\mathrm{p}=0.71$ )

The overall age distribution for all males was 8.54 years and for all females was 10.0 years. For Asians, the mean age for males was 9.18 years and for females was 10.57 years. For white children, the mean age for males was 7.00 years and for females was 9.25 years.

Corneal complications

There were 14 with punctate epithelial erosions ( 10 Asians and four white children). Comparing patients from both groups with severe disease, there was a relative prevalence of Asians by 6.75 to 1 (Fisher's test, $\mathrm{p}=0.001$ ).

In two cases, visual loss occurred after the onset of chronic allergic conjunctivitis from epithelial plaque and corneal pannus. Both were Asian.

\section{Comment}

Various studies have reported allergic eye disease to be more common among Asian and black patients. ${ }^{2-4}$ This may be due to genetic and/or environmental factors ${ }^{4-10}$

We found allergic eye disease to be more common in Asians than white children. It is possible that ocular allergy is multifactoria but perhaps with a greater genetic predisposition in certain ethnic communities. ${ }^{11}$ We could not comment on the prevalence of chronic allergic conjunctivitis in the community because of referral bias since we only see patients referred by GPs. The extent to which milder cases are treated in the community is not known but we feel that the more severe cases are the ones referred to our department.

Our findings highlight that allergic eye dis ease appears to be more common and complicated in Asian patients in the Bradford population. This potential risk of sight threatening disease means that they are more likely to require topical steroid treatment. This has led us to recognise that appropriately aggressive treatment is essential in these patients.

A J Singh, R S K Loh, J A Bradbury St James's University Hospital, Becket Street, Leeds LS9 7TF, UK

Correspondence to: Mr Anil J Singh, St James's University Hospital, Becket Street, Leeds LS9 7TF, UK; mraniljsingh@yahoo.co.uk

Accepted for publication 20 March 2003

\section{References}

1 Buckley RJ. Allergic eye disease-a clinical challenge. Clin Exp Allergy 1998;28(Suppl 6):39-43. 
2 Spraul CW, Lang GK. Allergic and atopic diseases of the lid, conjunctiva and cornea. Curr Opin Ophthalmol 1995;6:21-6.

3 O'Shea JG. A study of vernal

keratoconjunctivitis and other eosinophil-mediated external eye diseases amongst Palestinians. Ophthalmic Epidemiol 2000;7: 149-57

4 Montan PG, Ekstrom K, Hedlin G, et al. Vernal keratoconjunctivitis in a Stockholm ophthalmic centre-epidemiological, functional and immunologic investigations. Acta Ophthalmol Scand 1999;77:559-63.

5 Belfort R, Marbeck P, Hsu C, et al. Epidemiological study of 134 subjects with allergic conjunctivitis. Acta Ophthalmol Scand 2000;78:38-40.

6 Tabbara KF, Butrus SI. Vernal keratoconjunctivitis and keratoconus. Am J Ophthalmol 1983:95:704-5.

7 Totan Y, Hepsen IF, Cekic O, et al. Incidence of keratoconus in subjects with vernal keratoconjunctivitis: a videokeratographic study. Ophthalmology 2001;108:824-7.

8 Aberg N. Familial occurrence of atopic disease: genetic versus environmental factors. Clin Exp Allergy 1993;23:829-34

9 Dotterud LK, Kvammen B, Bolle R, et al. A survey of atopic diseases among school children in Sor-Varanger community. Possible effects of subarctic climate and industrial pollution from Russia. Acta Derm Venereol 1994;74:124-8

10 Freissler KA, Lang GE, Lang GK. Allergic diseases of the lids, conjunctiva, and cornea. Curr Opin Ophthalmol 1997:8:25-30.

11 Angioni AM, Fanciulli G, Corchia C. Frequency of and risk factors for allergy in primary school children: results of a population survey. Paediatr Perinat Epidemio 1989;3:248-55.

\section{CORRECTION}

We wish to apologise for an error in the extended report by Barry and König $(\mathrm{Br} J$ Ophthalmol 2003;87:909-16). On p 910 under the heading Orthoptic screening, point four of the bulleted list, line four should have read: "positive": visual acuity $\leqslant 0.4(10 / 25)$.

\section{NOTICES}

\section{Helping the blind and visually} impaired

The latest issue of Community Eye Health (No 45) discusses help for the blind, with an editorial by Sir John Wall of the Royal National Institute for the Blind on the right of blind people. For further information please contact: Journal of Community Eye Health, International Resource Centre, Inter national Centre for Eye Health, Department of Infectious and Tropical Diseases, London School of Hygiene and Tropical Medicine, Keppel Street, London WCIE 7HT, UK (tel: +44 (0)20 7612 7964; email: Anita.Shah@lshtm.ac.uk; website: www. jceh.co.uk). Annual subscription (4 issues) UK£28/US\$45. Free developing country applicants.

\section{Second Sight}

Second Sight, a UK based charity whose aims are to eliminate the backlog of cataract blind in India by the year 2020 and to establish strong links between Indian and British ophthalmologists, is regularly sending volunteer surgeons to India. Details can be found at the charity's website (www.secondsight.org.uk) or by contacting Dr Lucy Mathen (lucymathen@yahoo.com).

\section{SPecific Eye ConditionS (SPECS)}

SPecific Eye ConditionS (SPECS) is a not for profit organisation which acts as an umbrella organisation for support groups of any conditions or syndrome with an integral eye disorder. SPECS represents over 50 different organisations related to eye disorders ranging from conditions that are relatively common to very rare syndromes. The website acts as a portal giving direct access to support groups own sites. The SPECS web page is a valuable resource for professionals and may also be of interest to people with a visual impairment or who are blind. For further details about SPECS contact: Kay Parkinson, SPECS Development Officer (tel: +44 (0)1803 524238; email: k@eyeconditions.org.uk; website: www.eyeconditions.org.uk).

\section{The British Retinitis Pigmentosa Society}

The British Retinitis Pigmentosa Society (BRPS) was formed in 1975 to bring together people with retinitis pigmentosa and their families. The principle aims of BRPS are to raise funds to support the programme of medical research into an eventual cure for this hereditary disease, and through the BRPS welfare service, help members and their families cope with the everyday concerns caused by retinitis pigmentosa. Part of the welfare service is the telephone help line $(+44$ (0) 1280860363 ), which is a useful resource for any queries or worries relating to the problems retinitis pigmentosa can bring. This service is especially valuable for those recently diagnosed with retinitis pigmentosa, and all calls are taken in the strictest confidence. Many people with retinitis pigmentosa have found the Society helpful, providing encouragement, and support through the Help line, the welfare network and the BRPS branches throughout the UK (tel: +44 (0) 1280821334 ; email: lynda@brps.demon.co.uk; website: www.brps.demon.co.uk).

\section{Surgical Eye Expeditions International}

Volunteer ophthalmologists in active surgical practice are needed to participate in shor term, sight restoring eye surgery clinics around the world. Contact: Harry S Brown, Surgical Eye Expeditions International, 27 East De La Guerra, C-2, Santa Barbara, CA 93101-9858, USA (tel: +805 963 3303; fax: +805965 3564; email: hsbrown.md@cox.net or seeintl@seeintl.org; website: www.seeintl. org).

\section{Rise in organ transplant numbers}

According to UK Transplant, the UK has seen the highest number of organ transplants in six years. Last year (1 April 2002 to 31 March 2003) 2777 patients had their lives saved or dramatically improved through the generosity of 1064 donors. This equated to a $6 \%$ increase compared to the previous 12 months (1 April 2001 to 31 March 2002). Furthermore during 2002-3, the highest number of people benefited from a cornea transplant for five years (1997-98) and 240 more people had their sight restored than the previous year. For further information see UK Transplant's website (www.uktransplant.org.uk).

\section{Elimination of avoidable blindness}

The 56th World Health Assembly (WHA) considered the report on the elimination of avoidable blindness (doc A56/26) and urged Member States to: (1) Commit themselves to supporting the Global Initiative for the Elimination of Avoidable Blindness by setting up a national Vision 2020 plan by 2005; (2) Establish a national coordinating committee for Vision 2020, or a national blindness prevention committee to help implement the plan; (3) Implement the plan by 2007; (4) Include effective monitoring and evaluation of the plan with the aim of showing a reduction in the magnitude of avoidable blindness by 2010; (5) To support the mobilisation of resources for eliminating avoidable blindness The WHA also urged the Director-General to maintain and strengthen WHO's collaboration with Member States and the partners of the Global Initiative for the Elimination of Avoidable Blindness as well as aid in the coordination and support of national capability.

\section{MSc course in Community Eye Health}

The International Centre for Eye Health is offering a full time MSc course in Community Eye Health from 29 September 2003 to 19 September 2004. The course is not clinical and is specifically for eye health professionals wanting to work in the field of community eye health. The course is designed in keeping with the aims, priorities, and strategies of Vision 2020 - the Right to Sight. The course costs $£ 3939$ for home students and $£ 14110$ for overseas students. Further information: The Registry, 50 Bedford Square, London WC1B 3DP, UK (tel: +44 (0)20 7927 2239; fax: $+44 \quad(0) 207323$ 0638; email: Adrienne.Burrough@lshtm.ac.uk; website: www.lshtm.ac.uk).

\section{Ophthalmic Anesthesia Society (OAS) - 17th Scientific Meeting}

The 17th Scientific Meeting of the Ophthalmic Anesthesia Society (OAS) will be held 3-5 October 2003 at the Westin Michigan Avenue Chicago, Chicago, USA. Programme co-chairs: Marc Allen Feldman MD MHS and Steven T Charles MD. The CME joint sponsor is the Cleveland Clinic Foundation; CME hours are pending. Fees for OAS members are $\$ 300$; non-members $\$ 475$; students $\$ 50$.

Further details: OAS, 793-A Foothill Blvd, PMB 119, San Luis Obispo, CA 93405 USA tel: + 1805534 0300; fax: + l 805534 9030 email: info@eyeanesthesia.org; website: www.eyeanesthesia.org).

\section{Glaucoma Society 24th Annual Meeting and Dinner}

The Glaucoma Society 24th Annual Meeting and Dinner will take place on 20 November 2003, from 8:30 am to $5: 00 \mathrm{pm}$ at The Royal College of Physicians, London, UK. Further details: Ms Janet Flowers (email: glausoc@ukeire.freeserve.co.uk).

\section{Detachment Course with} international faculty on: Retinal and Vitreous Surgery with Case Presentations preceding the Annual Meeting of Iranian Society of Ophthalmology

The detachment course with international faculty on: Retinal and Vitreous Surgery with Case Presentations preceding Annual Meeting of Iranian Society of Ophthalmology will be held 
on 29-30 November 2003 and 1-4 December 2003 respectively, at the Razi Conference Center, Hemmat Hyw, Tehran, Iran. Further details: Scientific programme: Prof Ingrid Kreissig, University of Tuebingen, Schleichstr. 12, Breuningerbau, 72076 Tuebingen, Germany (tel: $\quad+49$ 7071 295209; email: ingrid.kreissig@med.uni-tuebingen.de). Local organisation: Dr Arman Masheyekhi, Dr Siamak Moradian, Dept of Ophthalmology, Labbanfinejad Medical Center, Pasdaran Ave, Boostan 9, Tehran, 16666, Iran (fax: +98 21254 9039; email: labbafi@hotmail.com).

\section{5th International Symposium on Ocular Pharmacology and Therapeutics (ISOPT)}

The 5th International Symposium on Ocular Pharmacology and Therapeutics (ISOPT) will take place 1 1-14 March 2004, in Monte Carlo, Monaco. Please visit our website for details of the scientific programme, registration, and accommodation. To receive a copy of the Call for Abstracts and registration brochure please submit your full mailing details to http:// www.kenes.com/isopt/interest.htm.
Further details: ISOPT Secretariat (website: www.kenes.com/isopt).

XVth Meeting of the International

Neuro-Ophthalmology Society

The XVth Meeting of the International NeuroOphthalmology Society will take place 18-22 July 2004, in Geneva, Switzerland.

Further details: Prof. A Safran, University Hospital Geneva, c/o SYMPORG SA, Geneva (fax: +4122 839 8484; email: info@symporg.ch; website: www.symporg. ch). 